Spring 3-2021

\title{
Early Identification of Sepsis: A Nurse Driven Protocol to Reduce Morbidity, Mortality and Hospital Costs
}

Ruth Biju

University of St. Augustine for Health Sciences, r.biju@usa.edu

DOI: https://doi.org/10.46409/sr.NIRV6419

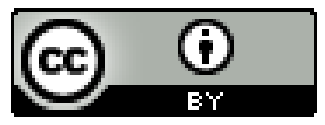

This work is licensed under a Creative Commons Attribution 4.0 License.

Follow this and additional works at: https://soar.usa.edu/scholprojects

Part of the Diseases Commons, and the Nursing Commons

\section{Recommended Citation}

Biju, R. (2021). Early Identification of Sepsis: A Nurse Driven Protocol to Reduce Morbidity, Mortality and Hospital Costs. [Doctoral project, University of St Augustine for Health Sciences]. SOAR @ USA: Student Scholarly Projects Collection. https://doi.org/10.46409/sr.NIRV6419

This Scholarly Project is brought to you for free and open access by the Student Research at SOAR @ USA. It has been accepted for inclusion in Student Scholarly Projects by an authorized administrator of SOAR @ USA. For more information, please contact soar@usa.edu, erobinson@usa.edu. 
Early Identification of Sepsis: A Nurse Driven Protocol to

Reduce Morbidity, Mortality and Hospital Costs

Ruth Biju BSN, RN

School of Nursing, University of St. Augustine for Health Sciences

This Manuscript Partially Fulfills the Requirements for the

Doctor of Nursing Practice Program and is Approved by:

Dr. Sheri Jacobson PhD, RN

Dr. Gregory Rogers, DNP, MBA, RN, NEA-BC, CCRN

March 25, 2021 


\begin{abstract}
Practice Problem: About 270,000 people die from sepsis every year, which is one person every 2 minutes, more than prostate cancer, breast cancer, and AIDS combined. It was identified that the organization had a good process in place for the treatment of severe sepsis but no process for early assessment of worsening symptoms of sepsis.
\end{abstract}

PICOT: The PICOT question that guided this project was: In adult inpatients (P), does the use of a nurse-driven sepsis screening tool (I) compared to not using a screening tool (C) affect early identification and treatment of sepsis $(\mathrm{O})$ within an 8-week period $(\mathrm{T})$ ?

Evidence: Ten high quality studies that met the inclusion criteria which supported using a nurse driven sepsis identification tool, were identified. The evidence demonstrated utilizing the tool, education of staff and integration of the tool into the Electronic Health Record were key factors for a successful project.

Intervention: Staff were trained on the Severe Sepsis Identification tool and utilized the tool in the EHR with the goal of reducing the number of patients developing severe sepsis when admitted to the hospital for any diagnosis.

Outcome: The evaluation of the outcome measures indicated that the number of patients who developed severe sepsis decreased from 12 , pre-implementation to 1 post-implementation. The number of those patients for whom the physician was notified within 30 minutes which is the standard notification time for the organization for any change in patient condition improved from 19 pre-implementation to 27 , post-implementation. Chi-square test showed a p-value of 0.001 demonstrating statistical significance in using the Severe-Sepsis Identification Screening tool to reduce the number of patients developing severe sepsis, whereas the p-value for physician notification times was 0.015 which revealed statistical insignificance in using the tool. 
Conclusion: The implementation of a nurse driven severe-sepsis identification tool for early identification of sepsis decreased the number of patients who developed severe sepsis and provided the evidence for clinical significance of the intervention. 


\section{Early Identification of Sepsis: A Nurse Driven Protocol to Reduce Morbidity, Mortality and Hospital Costs}

Nurses are at the forefront of patient care, and so they are in a unique position to make that first crucial assessment to detect sepsis. To understand the impact on sepsis and septic shock, nurses need to know the signs and keep up to date with the latest evidence-based best practices (American Association of Critical Care Nurses [AACN], 2019). Although the use of a screening tool for early detection of sepsis has been advocated widely (Drahnak et al., 2016; Gyang et al., 2016; Jones et al., 2015; Jung et al., 2018; O’Shaughnessy et al., 2017; Torsvik et al., 2016; Umscheid et al., 2015; Wawrose et al., 2015), the studies validating tool performance are scarce (Gyang et al., 2016). Using a simple screening tool for sepsis as part of the nursing assessment in an intermediate care setting may help identify early sepsis (Gyang et al., 2016). This nurse-driven Severe Sepsis Identification tool is a reliable and valid tool that has been used previously (Gyang et al., 2016), and the Doctorate in Nursing Practice (DNP) student has received permission from the author to use this tool (see Appendix B).

The purpose of this DNP project paper is to describe the introduction of an evidencebased Severe Sepsis-Screening tool as part of the nursing assessment done on every shift for patients admitted to the hospital. This procedure may allow for early identification of sepsis and prevent the development of severe sepsis. Additionally, this paper discusses the significance of the practice problem, the population, intervention, comparison, outcome, and time (PICOT)question, the evidence-based practice project framework and change theory, evidence search strategy and results, and evaluation, the themes from the evidence, practice recommendations, the project setting and overview, the implementation plan, the project evaluation plan, the plans for dissemination, and the conclusion. 


\section{Significance of the Practice Problem}

Sepsis is a significant healthcare burden. More than 30 million people around the world develop sepsis each year (Ruhumuliza et al., 2018). There are about 1.6 million sepsis cases in the United States (U.S.) annually (Ruhumuliza et al., 2018). About 270,000 people die from sepsis every year, which is one person every two minutes, more than prostate cancer, breast cancer, and AIDS combined (Sepsis Alliance, 2018).

In the United States, sepsis accounts for $6 \%$ of all hospitalizations and $35 \%$ of all deaths in the hospital (Sepsis Alliance, 2018). Sepsis is the leading cause of death in U.S. hospitals (Sepsis Alliance, 2018). In severe sepsis, the mortality rate is approximately 30\% (Gyang et al., 2016). Every hour sepsis treatment is delayed, the risk of mortality increases by about $8 \%$ (Sepsis Alliance, 2018). Approximately $17 \%$ of those who survive sepsis have severe persistent impairments (Ruhumuliza et al., 2018). An average of 38 amputations occur in the U.S. daily because of sepsis (Sepsis Alliance, 2018). Sepsis survivors often suffer from impaired quality of life and are $42 \%$ more likely to commit suicide among those hospitalized with infections. They have a shortened life expectancy (Sepsis Alliance, 2018).

Sepsis significantly affects patients and the healthcare system. Every year sepsis costs approximately $\$ 24$ billion and is the number one budget utilization for hospitalization (Ruhumuliza et al., 2018). Readmission due to sepsis is valued at about $\$ 2$ billion each year (Sepsis Alliance, 2018). In California, the rate of sepsis cases per 100 hospitalizations increased from $3.2 \%$ in 2010 to $5.9 \%$ in 2016 , while the rate of sepsis deaths went down from $24.5 \%$ in 2010 to $16.8 \%$ in 2016 indicating gains in identification and treatment such as the sepsis core measure set (Hospital Quality Institute, 2017). 
However, $80 \%$ of sepsis deaths can be prevented with rapid diagnosis and treatment (Sepsis Alliance, 2018). A simple sepsis-screening tool can be utilized as a part of the nursing assessment to identify early sepsis in medical-surgical patients admitted to the hospital. It is imperative for sepsis screening to be part of the daily assessment to influence outcomes positively. If screening is not done, the chances are that the patients who would have benefited from the interventions will be missed (Ruhumuliza et al., 2018).

\section{PICOT Question}

In adult inpatients (P), does the use of a nurse-driven sepsis screening tool (I) compared to not using a screening tool (C) affect early identification and treatment of sepsis (O) within eight weeks $(\mathrm{T})$ ?

\section{Population}

The population in this project was adult patients admitted to the hospital for any diagnosis. The project was conducted at a 268-bed Southern California hospital. Patients admitted to the emergency room, pediatrics, maternity, and COVID-19 floors were excluded.

\section{Intervention}

The intervention was a nurse-driven screening tool introduced to improve sepsis-related morbidity, mortality, and inpatient costs. The registered nurse for each patient completed the tool, which was incorporated into the electronic health record (EHR) at the beginning of each shift as part of the patient assessment (Gyang et al., 2016). This tool screened for the presence of Systemic Inflammatory Response Syndrome (SIRS), which is an exaggerated defense response by the body to a stressor like infection, surgery, trauma, acute inflammation, ischemia, malignancy, or reperfusion. Sepsis is SIRS with a suspected source of infection (Chakraborty \& Burns, 2020). 
Chakraborty and Burns (2020) defined SIRS as meeting any two of the following criteria:

- Body temperature under 36 degrees Celsius or over 38 degrees Celsius

- A heart rate of more than 90 beats/minute

- Respiratory rate more than 20 breaths per minute or partial pressure of $\mathrm{CO} 2$ less than 32 $\mathrm{mmHg}$

- Leukocytes were less than 4000 or greater than 12000 /microliters or more than $10 \%$ immature forms or bands (Chakraborty \& Burns, 2020, p. 4).

This is the first tier. If patients met more than two of the above criteria, the nurse moved to the second tier of the tool, which involved looking for an infection source. If there was no source, then further screening was discontinued. If the patient met the criteria for a positive sepsis screen, then the nurse moved on to the third tier, which involved the assessment of organ dysfunction, which indicated severe sepsis. If positive for sepsis or severe sepsis, then the physician was notified, and sepsis management was initiated (Gyang et al., 2016).

\section{Comparison}

Previously, there was no screening tool in use to assist with the early diagnosis of sepsis. Once the screening tool was implemented, the sepsis rate was compared to the sepsis rate before the tool was implemented. The comparison group were adult inpatients admitted with any diagnosis during the period of study.

\section{Outcome}

This project's desired outcome was to identify and treat sepsis with the screening tool's implementation. Early identification of sepsis and treatment initiation reduces sepsis-related mortality and is cost-effective (Gyang et al., 2016). It also reduced complications of sepsis. 


\section{Timeframe}

The timeframe for conducting the evidence-based practice project was eight weeks. Data were collected pre-and post-implementation of the tool to see if the screening tool would reduce the morbidity and mortality rates. The pre-implementation data were collected for four weeks. The nurses were trained on how to use the tool in the EHR for the patients using a PowerPoint presentation. Then post-implementation data were collected for four weeks.

\section{Evidence-Based Practice Framework \& Change Theory}

\section{Evidence-Based Practice Framework}

A theoretical framework is a blueprint or guide for a DNP project, and it is based on an existing theory. The theoretical framework should guide the project all the way from defining the problem, to the literature survey, methodology, presentation and discussion of the findings, and conclusions. To select the right theoretical framework, one must have a thorough understanding of the problem, significance, purpose, and practice problem (Adom et al., 2018).

The Stetler model developed in the 1970s was used to help postgraduate nurses apply project results to their professional performance. The model has guidelines for translating evidence into steps of implementation (Camargo et al., 2017). This model has five phases.

1. Preparation, where the problem is identified and validated (Keele, 2012). It was validated that although treatment protocols were available for the treatment of severe sepsis, the organization did not have a tool to assess patients before they go into sepsis.

2. Validation is done when the articles are critiqued and evidence is synthesized (Keele, 2012). The DNP student collected articles and reviewed them for validation. 
3. Comparative evaluation is when the cumulative findings are synthesized and usage is decided (Keele, 2012). Upon reviewing the evidence-based literature, the DNP student decided what articles to be used.

4. The translation/application phase occurs when a proposal for practice change is developed and strategies for dissemination and planned changes are considered (Keele, 2012). The proposal was to incorporate the Severe Sepsis Identification tool after obtaining permission from the author. The tool was integrated into the EHR, and patients were assessed every shift using the tool by the registered nurse (RN). This proposal was presented to stakeholders. Once approved, the change was implemented in the organization after educating the R.N.s. The plans for continued utilization of the tool were disseminated.

5. The evaluation phase can be formal or informal (Keele, 2012). Outcomes were evaluated to determine the percentage of patients who went into severe sepsis after implementing the sepsis identification tool.

\section{Change Theory}

Lewin's change theory was developed by Kurt Lewin (1951) as a three-stage model of change known as the unfreeze-change-refreeze model. This required that prior learning was to be rejected and replaced. Unfreezing involved making it possible for people to let go of something counterproductive. It was crucial to overcome individual resistance (Lewin, 1951). Nurses understood that there was a problem of severe sepsis, and change was needed. The changing state begins when there is a change in thought, behavior, and feelings (Lewin, 1951). 
Senior management, which included the chief nursing officer, the inpatient clinical director, and the director of education, were provided with evidence-based practice guidelines and guidelines on how the assessment tool could improve the quality of care. They were extremely supportive of this endeavor. The refreezing stage establishes the new habit that becomes the "standard operating procedure" (Lewin, 1951). The new habit involved assessing the patient before every shift and as needed using the new Severe Sepsis Identification tool. The I.T. team was involved in identifying a workflow to incorporate the tool into the EHR and ways to troubleshoot in case of any problems with the tool. In-service was provided to the entire staff on how to use the new tool.

\section{Evidence Search Strategy}

A thorough literature search was conducted to address the question: In adult inpatients, does the use of a nurse driven-sepsis screening tool compared to those not screened using the tool affect early identification and treatment of sepsis within a thirty-day period? The Cumulative Index to Nursing and Allied Health Literature (CINAHL), ProQuest, and PubMed databases were used to conduct a comprehensive electronic search. The search terms used were sepsis, early identification of sepsis, systemic inflammatory response syndrome, and nursedriven tool. Inclusion criteria consisted of articles published between 2015 and 2020, peerreviewed journals, adults 19 years and older, and journals in the English language.

The search results were as follows: CINAHL yielded 40 citations, PubMed yielded 170 citations, and ProQuest yielded 3,826 citations. In the ProQuest database, the inclusion of the term "inpatient" reduced the number of articles to 141. All articles were reviewed for relevance and, after reading the title and abstract, any article that included pediatrics and Emergency Room were removed. Relevant articles were hand-searched, duplicates were removed, editorials and 
periodicals were excluded, and 20 articles were handpicked. Upon further reviewing the quality and level of research, the number of articles was reduced to 10.

\section{Evidence Search Results}

Searches of the CINAHL, PubMed, and ProQuest databases yielded 1,036 articles. The results included peer-reviewed articles from the years 2015 to 2020, written in the English language, and contained data for adults over the age of 18. See the Preferred Reporting Items for Systemic Reviews and Meta-Analysis (PRISMA) diagram (Appendix A) Figure A1 for further details.

The John Hopkins Nursing Evidence-Based practice tool was used to appraise the articles' quality and strength critically. The evidence levels were divided into five levels, from Level I to Level V. The articles' quality was rated as A for high-quality, B for good-quality, or C for low-quality (John Hopkins Medicine, n.d.). See (Appendix C) for the description of the John Hopkins Nursing Evidence-Based Practice tool in detail.

Most of the studies for this DNP proposal were either observational studies or Pre-Post intervention studies. Observation studies were comparable to RCTs and could complement RCTs in hypothesis generation, defining clinical outcomes, and establishing questions for future RCTs (Song \& Chung, 2010). The pre-post intervention studies were also cohort studies that were also comparable to RCTs (Oregon Health and Science University, 2020). Out of the ten articles reviewed, eight articles were level I, and two articles were level II. Five of the articles were level A while four of the articles were level B, and one article was level C. A summary of the primary articles reviewed can be found in (Appendix D). 


\section{Themes with Practice Recommendations}

The literature synthesis revealed enough data from the literature to state that early identification of sepsis could reduce morbidity, mortality, and hospital stay. The literature showed that sepsis was a significant health care burden. Most of the studies showed how an appropriate tool could help identify sepsis early to reduce morbidity, mortality, and hospital stay. An observational study by Gyang et al. (2016) revealed how a simple screening tool used by the bedside nurse could successfully identify sepsis early and lead to a timely diagnosis and treatment in medical-surgical patients. The screening tool is a three-tiered screening tool used by the bedside nurse.

Drahnak et al. (2016) revealed that providing nurses with appropriate tools such as electronic screening and scripting could be a strong foundation for building a sepsis treatment program. Jones et al. (2015) discussed early detection of sepsis and proper treatment. O’Shaughnessy et al. (2017) identified routine sepsis screening that led to an improvement in limiting sepsis progression and a decrease in mortality, morbidity, and healthcare costs. Torsvik et al. (2016) identified those ward nurses, when they were at the forefront for sepsis diagnosis, could increase survival and decrease septic shock. Umscheid et al. (2015) concluded that an automated prediction tool identifies patients at risk and results in timely sepsis care reducing mortality rates.

Wawrose et al. (2015) revealed that a sepsis screening score performed twice a day was more effective in identifying sepsis. Drahnak et al. (2016) talked about a nurse education bundle to recognize signs of sepsis. Jones et al. (2015) also discussed the education of nurses as one of the four key elements for early recognition of sepsis. The study by O'Shaughnessy et al. (2017) led to an improvement in early identification by nurse education related to sepsis. Jones et al. 
(2015) talked about integrating the sepsis-screening tool into the EHR as one of the four key elements in early sepsis identification.

Clinical Decision Support (CDS) integrated into EHR in a hospital setting effectively promoted early recognition of sepsis (Amland \& Hahn-Cover, 2019). The integration of a visual decision support system would help providers adhere to Surviving Sepsis Guidelines (Jung et al., 2018). Setting up and implementing evidence-based screening and response protocols would help reach the goal of early sepsis identification (Jones et al., 2015). However, Churpek et al. (2015) suggested that screening hospitalized patients with SIRS criteria for early identification of sepsis would be impractical as almost half of the patients developed SIRS at least once during their hospitalization.

A synthesis of the literature identified evidence-based methods in the early identification of sepsis. All the studies conducted were in a hospital setting and included patients in medicalsurgical or ICU settings. Three of the studies were observational studies, and four of them were pre-post intervention studies. Two studies were continuous cohort studies. The main themes that emerged from the synthesis were a nurse-driven sepsis identification tool, nurses' education, integration of the tool into the EHR, and developing protocols for using the tool. SIRS was used as a basis for the development of the tool.

\section{Nurse-Driven Sepsis Identification Tool}

The SIRS identification tool was found to be effective in multiple studies. Drahnak et al. (2016), Jones et al. (2015), Jung et al. (2018), O’Shaughnessy et al. (2017), Torsvik et al. (2016), Umscheid et al. (2015), and Wawrose et al. (2015) were deemed high-quality studies in the early identification of sepsis. The sepsis tool based on SIRS consists of a three-tiered screening assessment that was either paper-based or integrated into the EHR and was completed by the 
bedside R.N. The first tier was screening for the presence of SIRS, and the parameters included temperature $>38^{\circ} \mathrm{C}$ or $<36^{\circ} \mathrm{C}$, heart rate $>90$, white blood cell count $>12,000$ or $<4000$ or $>10 \%$ bands, respiratory rate $>20$ or partial pressure of carbon dioxide $(\mathrm{PaCO} 2)<32 \mathrm{~mm} \mathrm{Hg}$. This was only scored if the symptoms had developed in the last eight hours (Gyang et al., 2016).

If patients met $\geq 2$ SIRS criteria, then the nurse moved to the second tier, identifying any source of infection. If there was no source of infection, then the screening was discontinued. If there was a source of infection, the nurse would move to the third tier of screening which involved assessing for any organ damage (Gyang et al., 2016).

\section{Education of Nurses}

Jones et al. (2015) identified that nurses need to be provided in-service training on signs and symptoms and the impact of sepsis. Bedside nurses need to demonstrate mastery of the subject before they used the screening tool on patients. Drahnak et al. (2016) concluded that a 30-minute education would increase nurses`comfort level using the tool and would serve as an annual competency tool and a tool for new hires' education. O'Shaughnessy et al. (2017) implied that nurses' education regarding sepsis's pathophysiology helped to understand screening parameters. Education can be done at the time of implementing the tool, annually, and at the time of new hire.

\section{Integration of Screening Tool into Electronic Health Records}

According to Amland and Hahn-Cover (2019), the approach of sepsis CDS integration into EHR is effective towards early recognition of sepsis in a hospital setting. There was a possibility of some alerts being interpreted as false positives, but the measure of accuracy could be improved by conduction for different types of diagnostic testing. Houston Methodist Hospital $(\mathrm{HMH})$ initially had a pen and paper version, and nurses had difficulty translating the 
parameters. Transcription errors were eliminated with the integration of the tool into the EHR. It was also found to save time (Jones et al., 2015). The integration of CDS in the ICU setting would allow providers to adhere to sepsis guidelines to identify and treat surgical patients with infections and improve the quality of care (Jung et al., 2018).

\section{Developing Protocols for Using the Tool}

The development of an evidence-based screening and response protocol was considered part of the early recognition of sepsis. The bedside nurses conducted sepsis screening on hospital admission, at 12-hour intervals, and on any changes in clinical condition. Positive patients were evaluated by another responder who was a Nurse Practitioner at HMH. The initiative of definitive therapy would take place within one hour of a positive screen. The evaluation and treatment protocols for positive patients were based on recommendations from guidelines for managing severe sepsis and septic shock from the Surviving Sepsis Campaign, along with consensus recommendations from a trans-disciplinary panel of clinicians from HMH (Jones et al., 2015).

Evidence-based treatment for sepsis can improve survival. Delays in recognition and treatment of sepsis can lead to bad outcomes. A multidisciplinary approach was needed in the early identification of sepsis.

\section{Practice Recommendations}

Based on a thorough and rigorous review of the literature, the PICOT question was answered, recommending the nurse-driven Severe Sepsis Identification tool using the SIRS criteria for early identification and treatment of sepsis in adult patients. The results from the evidence and themes can be found in (Appendix D). The nurse-driven tool is attached (Gyang et al., 2016). (See Figure A2 in Appendix A). According to Gyang et al. (2016), patients screened 
using a 3-tier nurse-driven sepsis assessment tool used every eight hours was a way to identify early sepsis. Screening tool sensitivity and specificity were respectively $95 \%$ and $92 \%$. The positive predictive value was $54 \%$, and the negative predictive value was $99 \%$, with an overall test accuracy of $92 \%$.

The project by Drahnak et al. (2016) concluded that a 30-minute education for nurses on sepsis pathophysiology and assessment increased the nurses`knowledge, and this was analyzed using a pre and post-test after the education. The nurses rated themselves as more knowledgeable on sepsis after the education. A 10-question pre and post-test showed a statistically significant difference with all questions $\mathrm{p}<0.001$. A chi-square test showed statistical significance in improved sepsis screening post-education intervention with $\mathrm{p}<0.0001$.

In the research done by Jones et al. (2015), the pen and paper version was effective in that nurses used the tool, but nurses had difficulty translating the number to a scale. This problem was solved by integrating the tool into the EHR. Integrating the tool eliminated interpretive and mathematical errors. Once the nurse entered the data and saved the assessment, it automatically calculated the score.

Setting up response protocols was also important. According to Jones et al. (2015), the screening was completed once every 12 hours or as needed for any clinical condition changes. Once a patient was screened positively using the tool, a second responder, who was usually a nurse practitioner, conducted a second evaluation and initiated definitive therapy. Treatment was based on the Surviving Sepsis Campaign: International Guidelines for Management of Severe Sepsis and Septic shock and consensus recommendation of an interdisciplinary panel of HMH clinicians.

Practice recommendations for this project included: 
- Establishing a nurse-driven Severe Sepsis Identification screeing tool for early identification of worsening sepsis

- Integration of the tool into the EHR

- Establishing a protocol for the use of the tool

- Education of nurses on the use of the tool and protocol

- A process for identification of errors in the use of the tool

- Remediation for nurses who do not use the tool or uses it incorrectly

\section{Setting, Stakeholders, and Systems Change}

The setting for the DNP scholarly project was a 268-bed acute care hospital located in Southern California. The organization is a general medical and surgical hospital operated by the Foundation Hospital. Specialties at this hospital included cancer, endocrinology, urology, orthopedics, diabetes, and gynecology. The organization's mission is to provide high-quality health care that is affordable, improve its members' health, and the communities they serve. The vision of the organization is to help people thrive and create the healthiest communities in the nation.

\section{Organizational Need}

An organizational needs assessment and gap analysis were done to identify current practices and areas needing improvement. It was identified that the organization had a good process in place for the treatment of sepsis. However, it was important to have an early identification tool in place to reduce the number of patients developing severe sepsis or septic shock. Since the Centers for Medicare and Medicaid Services (CMS) does not provide for 
hospital reimbursement acquired infections, and the hospital will have to bear the expenses of the patient's hospitalization due to severe sepsis, this tool allowed for early identification and treatment of sepsis, thus reducing the hospital stay of the patient, and in turn, reducing the hospital cost. The facts were presented to the leaders, and it was decided to implement this project, which is early identification of severe sepsis using a nurse driven tool.

\section{Organizational Support and Stakeholders}

The inpatient clinical director expressed a need to introduce a Severe Sepsis Identification screening tool to identify sepsis early and reduce the rate of severe sepsis. The organization has wanted to do this project for some time. The leadership was supportive of this project. The different stakeholders in this project were the patient, inpatient clinical director, sepsis coordinator, inpatient nurses, department administrators of the different units, physicians, certified nursing assistants, and the informaticist. Organizational support was confirmed with a letter of support from the inpatient clinical director.

\section{Sustainability}

Sustainability for this project involved continuous monitoring of the use of the Severe Sepsis-Screening tool. Since this tool was embedded into the EHR and will be part of the nurse's assessment done every shift, it will be easy to monitor the tool's effectiveness and compliance. The sepsis coordinator will continue to monitor the tool's effectiveness monthly for the use of the tool by the nurses for effectiveness, completeness, and compliance. Education was provided to the nurses before implementing the project and new hires using the screening tool.

\section{Strengths, Weaknesses, Opportunity, and Threats Analysis}

The Strengths, Weaknesses, Opportunities, and Threats (SWOT) analysis allows leaders to assess an organization for strengths, weaknesses, opportunities, and threats and is a time-tested 
and useful leadership tool. The SWOT analysis is a systematic way of thinking about vulnerable areas that need improvement or development (Blayney, 2008). The organization's SWOT analysis revealed various strengths, weaknesses, opportunities, and threats (see Appendix E). Having a sepsis coordinator was certainly a strength for this project, especially in terms of sustainability. Interdisciplinary team support was a strength, and the organization's plan to introduce this tool for some time, and support from the organization contributed to this project's strength. False-positive or negative results were a weakness that cannot be overlooked. This project was a great opportunity to reduce mortality and morbidity rates and reduce hospital costs due to reduced hospital stays. The increased workload of staff and wrong diagnosis due to falsenegative screening could be perceived as a threat.

\section{System-Level for Evidence-Based Change}

The Stetler model was a guide to this evidence-based change. This model reflects a practitioner-oriented approach within the context of evidence-based practice. The five phases of this model include:

1. Preparation phase

2. Validation phase

3. Evaluation/decision-making phase

4. Translation/application phase

5. Evaluation phase (Stetler, 2001).

The preparation phase included the phase of searching and selecting sources of research evidence and affirming priority. The validation phase included identifying the evidence-based practice project details available and studying the sources to identify evidence available. The evaluation or the decision-making phase comprised of showing the evidence of current practice 
and substantiating the evidence through the research articles available to the leaders, suggesting the change, and obtaining their permission. The translation or application phase involved applying the practice recommendation into practice. This included implementing the nursedriven sepsis protocol after integration into the EHR by the I.T. team and establishing protocols for the same. The evaluation phase involved evaluating the tool for its use and identifying any barriers in its use, rectifying them, and disseminating the results.

\section{Implementation Plan with Timeline and Budget}

The project's vision and mission were congruent with the vision and mission of the organization, which is to improve the health of the members by early identification of sepsis to reduce the morbidity and mortality rates among the members.

\section{Objectives}

The short-term objectives include:

- Use an established evidence-based nurse-driven Severe Sepsis Screening tool for early identification of sepsis

- Develop a protocol for the use of the tool

- Integrate the tool into the EHR

- Educate nurses on how to use the tool before implementing the project The long-term objectives include:

- Reduce the rate of severe sepsis or septic shock by $\geq 1 \%$ during the period of the evidencebased practice project

- Reduce hospital costs by reducing the length of stay of septic patients

- Continued evaluation by the sepsis coordinator on the use of the tool for relevance and completeness 
- Disseminate the project to other facilities at the regional level

\section{Change Model and Practice change}

The model used for this project was Lewin's theory of change. During these complex health care times, inter-professional collaboration is needed to improve and sustain the best outcomes for high-quality and safe patient care. Lewin's three-step model for change consists of three steps: unfreezing or creating problem awareness, changing, or creating the needed change, and refreezing, so the change becomes a habit (Lewin, 1951). The three major concepts of the theory were driving forces, restraining forces, and equilibrium. Driving forces pushed in a direction for a change to occur. Restraining forces countered the driving forces opposing change. Equilibrium was a state where the driving forces equaled the restraining forces, and no change occurred. Equilibrium could be raised or lowered to allow the desired change to happen (Lewin, 1951).

\section{Unfreezing Phase}

Unfreezing starts with a motivation to change or recognize that change needs to occur (Lewin, 1951). Management had identified that there was an increased need for early identification of sepsis among inpatients. To create an environment for change, evidence-based guidelines were needed to improve quality, achieve objectives, and reduce health care expenditure. Regular meetings were conducted with the sepsis coordinator and informaticist. The inpatient clinical director was updated regularly on the progress of the project planning. There could be staff resistance due to increased workload. However, the staff was educated on how the tool could be used to identify sepsis early to reduce morbidity, mortality, and hospital stay. An interdisciplinary team was developed, which consisted of front-line nurses, physicians, charge nurses, department managers, the informaticist, and the phlebotomist. During this stage, the 
informaticist was involved in planning for the integration of the sepsis identification tool into EHR.

\section{Change Phase}

The change phase includes the planning and implementation stages of the project (Lewin, 1951). It was important to set timelines for the implementation, decide on staff's educational needs, and develop an effective workflow. Strong support from leadership was important at this stage. Early identification of sepsis by using a nurse-driven tool was the prime goal of this project. Education was provided to the nurses on the importance of early recognition of sepsis and how to use the Severe Sepsis Identification tool. The nurses began using the tool to identify early sepsis and followed protocol in using the tool. The following establishes the protocol for the use of the sepsis tool:

- Screening done once every shift

- $\quad$ Screening for SIRS criteria

If positive, identify a possible source of infection

- If source identified, notify the physician

If no source identified, discontinue screening

- If source identified, continue assessment for severe sepsis

- If severe sepsis identified, call the Rapid Response team or physician

- Document time of physician notification and time of treatment initiation

\section{Refreezing Phase}

Refreezing was the final stage and is the period for stabilizing and evaluation (Lewin, 1951). Continuous support was provided to the front-line staff with training as needed until everyone was comfortable with the change. The evaluation was done at this stage to make sure 
goals were achieved in reducing the rate of severe sepsis and septic shock, and the change was made permanent. Challenges encountered were also evaluated for future reference. Data were analyzed during this time and presented to front-line staff and management. The results and dissemination plan were also finalized and presented. The nurses recognized that the screening tool was part of the daily assessment that was expected from them.

\section{Interprofessional Collaboration}

Working as a team was essential for the success of this project. Sepsis education and team collaboration were integral in treating patients with sepsis. Nurses were educated on the use of the tool before implementation began. The different team members included the project manager, front-line nurses, physicians, department administrators from the various floors where the project was implemented, nursing assistants, educators, sepsis coordinator, the informaticist, lab personnel, and respiratory staff. The team worked on how to implement the project and develop policies and procedures to use the tool. All team members worked towards a common goal of reducing the rate of development of severe sepsis.

\section{Project Timeline}

The first step towards implementing the project was completing an organizational assessment and a literature review. Evidence-Based Practice Review Council (EPRC) approval was obtained from The University of St Augustine for Health Sciences and Institutional Review Board (IRB) approval was obtained from the organization. After appropriate approvals, data on the rate of patients developing severe sepsis/ septic shock pre-implementation of the tool were collected for four weeks. Education and training of staff on the appropriate use of the sepsis identification tool and the protocols began. See (Appendix F) for PowerPoint on Severe Sepsis Identification tool nurse orientation. The tool was integrated into the EHR with the informaticist 
and staff's help, and they were ready to use the tool. After the tool was implemented, data were collected for four weeks to determine the tool's effectiveness. The total time for implementation was eight weeks. See (Appendix G) for a detailed timeline for the project.

\section{Resources and Budget}

The project's resources included the DNP student, sepsis coordinator, informaticist, data analyst, staff educators, inpatient clinical director, and front-line R.N.s. Since it was a need for the organization, minimal cost was involved. R.N.s were educated and trained outside of their work hours and were paid for their time. I.T. staff involved in embedding the tool into the EHR performed this as part of their roles in the organization, and no separate budget was involved. Data analysts running reports also performed their duties as part of their role in the organization. Other staff involved in the project performed this as part of their roles in the organization. A detailed budget is included in Table 1A in (Appendix A).

\section{Role of Doctorate in Nursing Project Manager}

The DNP student's role was to be responsible for the successful initiation, planning, coordination of the team members, supervise the project, and provide for closure of the project. A strong leader is essential to achieve the goal and for the success of the project. The project manager set deadlines, scheduled meetings, and assigned tasks. As a leader, the project manager motivated the team and helped problem-solve. Communication with team members was an important aspect of this project. Having support from management was essential for the success of this project.

\section{Results}

To determine if the results of the project were significant, several areas were evaluated. The primary outcome measure and goal was to identify sepsis early and reduce the rate of severe 
sepsis, using the Severe Sepsis Identification tool, which was implemented through December 2020. During that period, there was only one patient who developed severe sepsis as compared to 12 patients during the pre-implementation phase in November 2020. This showed that the sepsis identification tool produced clinically significant results due to the reduction in the number of patients who developed severe sepsis. The DNP student collected data from the EHR of the participants. All data were collected after EPRC approval from the University of Saint Augustine and data-only approval from the facility's IRB committee.

\section{Data Collection}

The different data collected included the following:

- Number of patients who developed severe sepsis pre-and post-implementation.

- Number of patients for whom the physician was notified within 30 minutes pre-and postimplementation. It is the standard of practice (SOP) of the organization to notify physicians of any changes in a patient's condition within 30 minutes.

- Number of patients transferred to a higher level of care pre-and post-implementation.

- Length of hospital stays pre-and post-implementation.

Data collected included admission and discharge diagnosis, length of hospital stay, if the patient was positive for SIRS from the sepsis identification tool, time of sepsis identification, and time when the physician was notified. The data collected also included the number of those transferred to a higher level of care. The data collection form is attached to Table H1 ( Appendix H). There was no missing data found as the sepsis identification tool had wild cards to be completed, and if wild cards were not completed, the chart could not be closed. Thus, all staff had to comply with using the sepsis identification tool each shift. The sepsis identification tool's reliability was determined by identifying true and false positives, and true and false negatives. 
This was done by going back to the EHR of the patient to see if the International Classification of Disease (ICD) -9 code for sepsis was updated in the chart within 24 hours of the positive or negative screen. True positives were those whose ICD-9 codes were updated to sepsis after a positive screen; false positives were those whose ICD-9 codes were not updated to sepsis, despite a positive screen. True negatives were those patients who had a negative screen and did not have an ICD code for sepsis, and false negatives were those who had an ICD-9 code for sepsis despite being screened negative. The data collected on all 30 patients' postimplementation showed an updated ICD-9 code for sepsis or severe sepsis.

\section{Selection of Participants}

Participants of the DNP project included adults admitted during the eight weeks for the period of the evidence-based practice project. The project excluded patients admitted to the emergency department, pediatric, maternity, and COVID floors. The project also excluded patients admitted with a diagnosis of sepsis.

\section{Data Analysis}

This was a quantitative project evaluation design, and pre-and post-implementation data were collected and measured to compare the project's results. An Intellectus software was used to compare pre-and post-intervention data. Descriptive statistics were used to display data visually. A bar chart was used to compare the frequency and rate of severe sepsis and the frequency and rate of those patients who met SOP guidelines for physician notification times pre-and post-implementation. Statistical significance was calculated using an unpaired chi-square test with a p-value of 0.05 for statistical significance. The different measures used were outcome, process, balance, financial, and sustainability measures. The different measures, benchmarks, data types, and statistical tests were included in a table in Table H2 (Appendix H). 


\section{Outcome Measures}

Outcome measures included calculating the frequency and rate of patients diagnosed with severe sepsis pre-and post-implementation. The rate and frequency of the number of patients for whom the physician was notified within 30 minutes of a positive screen for sepsis were also calculated pre-and post-implementation. During the pre-implementation phase, out of the 30 patients (100\%), 12 patients $(40 \%)$ went into severe sepsis. The benchmark was $40 \%$, which was the rate of severe sepsis pre-implementation, and the goal was to reduce the rate of severe sepsis by $\geq 1 \%$. During the post-implementation phase, out of the thirty patients (100\%), only one patient (3\%) went into severe sepsis (see Appendix H) Figure H1. A chi square test was conducted to compare pre-and post-implementation rates of sepsis that yielded a p value of < .001 (see Table1) showing that the reduction in severe sepsis was statistically significant due to the use of the tool and not by chance. 


\section{Table 1}

\section{Sepsis/Severe Sepsis}

Filtered By: Study (Preimplementation and Postimplementation)

\section{Descriptives}

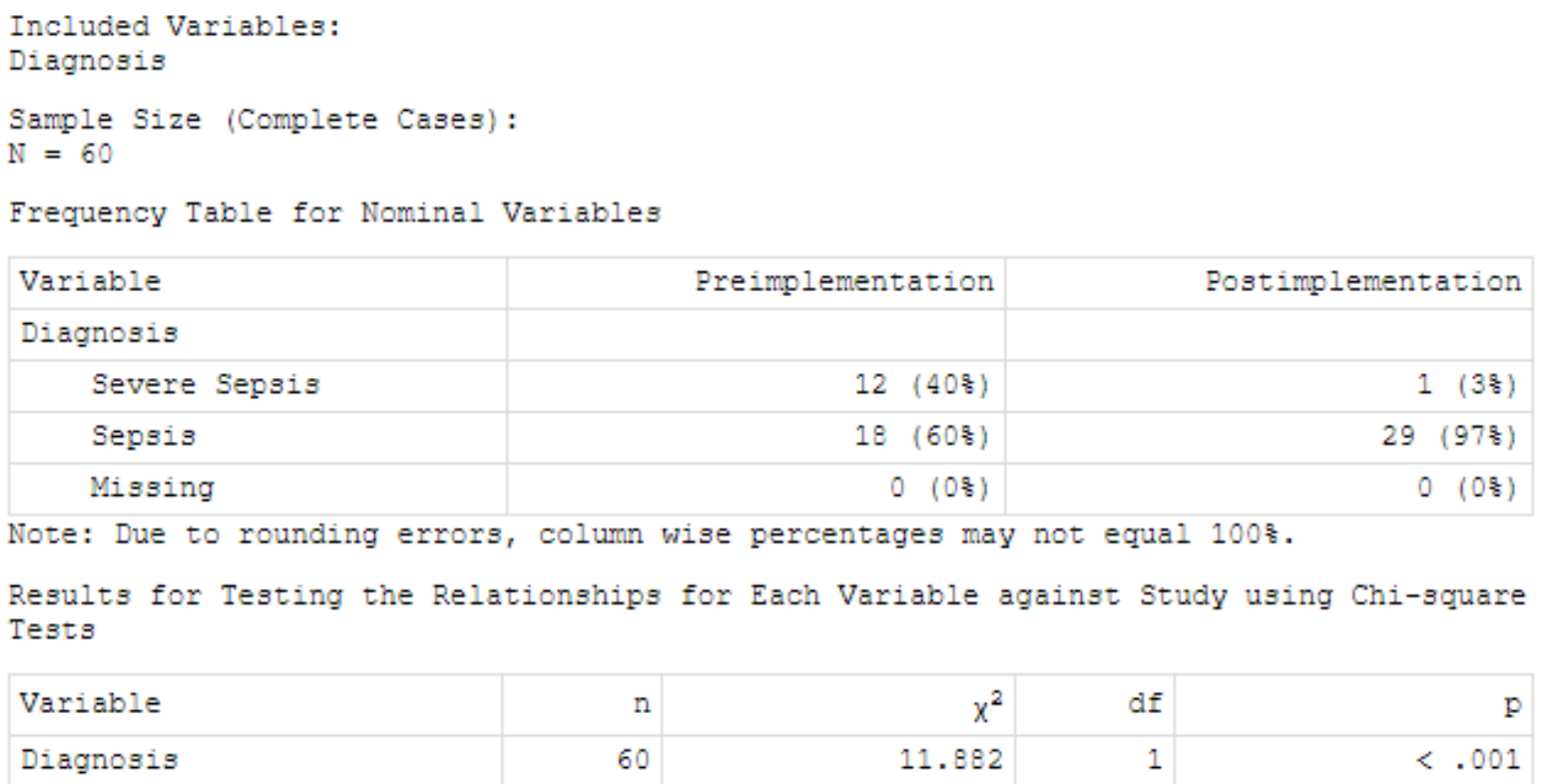

During the pre-implementation phase, 19 patients (41\%) out of the 30 patients (100\%), notification to the physician took less than 30 minutes. During the post-implementation phase, the number of patients who met the physician notification timeline increased to 27 (59\%) (see Appendix H) Figure H2. The benchmark was $>41 \%$, and the goal was to have the physician notified on time for $42 \%$ of the patients. Post-Implementation in $59 \%$ of the patients, the physician was notified on time. The number of patients for whom the physician was notified of the change in condition within thirty minutes yielded a p-value of 0.015 ( see Table 2) using the chi-square test, was statistically insignificant, showing that the reduction in physician notification times were by chance. 


\section{Table 2}

\section{Physician Notification Time}

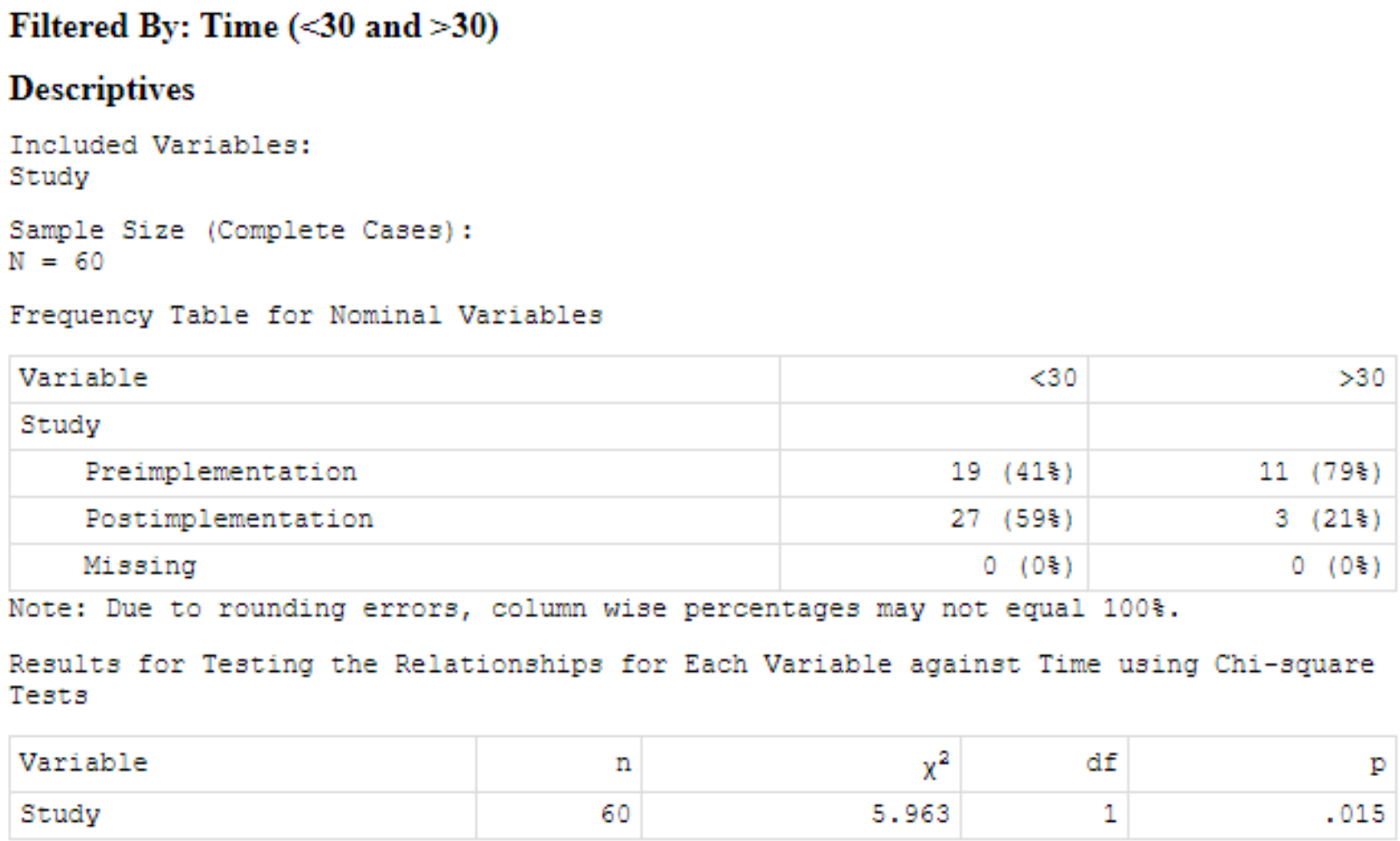

\section{Process Measures}

The process measure in this project was to make sure $100 \%$ of the nurses complied with the Severe Sepsis-Screening tool, which was achieved by creating wild cards. Charge nurses were made responsible for ensuring that the chart was completed before the end of each shift. The goal of $100 \%$ of the process measure was achieved.

\section{Balance Measures}

Balance measures included decreasing transfer of patients to a higher level of care. During the pre-implementation phase, ten patients were transferred to a higher level of care. In contrast, only one patient was transferred to a higher level of care during the postimplementation phase. The benchmark was to reduce the number of patients transferred to a 
higher level of care to less than 10 , and the goal was to reduce it to $\leq 9$, but the current statistics showed that only one patient was transferred to a higher level of care post-implementation. None of the patients died during the post-implementation phase due to sepsis.

\section{Financial Measures}

Finance measures included expenses and returns. The R.N.s each received training for a total of two hours outside their work hours. The I.T. personal and sepsis coordinator worked during normal work hours, and no separate budget was needed. The expenses for the level of care post-implementation were reduced as only one patient transferred to a higher level of care. The length of stay post-implementation was about 4.4 days compared to the length of stay preimplementation, which was about 8.1 days (see Appendix H) Figure H3. The benchmark for the length of stay was 8.1 days, and the goal was to reduce it to $\leq 7.1$ days. The current statistics showed the length of stay as 4.4 days post-implementation. The cost of hospitalization was not calculated, but since the length of stay decreased, hospitalization cost also decreased.

\section{Sustainability Measures}

Sustainability measures include nurses' continued education by the sepsis coordinator and educating them during new hire orientation to use the sepsis identification tool. The benchmark is $100 \%$, and the goal to educate $\geq 95 \%$ of the new hires. The sepsis coordinator will also continue to monitor the tool's effectiveness monthly to use the tool by the nurses for effectiveness, completeness, and compliance.

\section{Protection of Human Rights and Privacy}

Data were collected, analyzed, and stored by the DNP student. No private health information was utilized, as all data collected were de-identified to protect patients' privacy. To accomplish this, each patient was assigned a participant number used during the project in 
exchange for patient identifiable information. The study data were stored on a passwordprotected Microsoft Excel spreadsheet on a password-protected computer within the medical center that only the DNP student can access. At the end of the project, all data were securely disposed of according to the medical center's policy and procedure.

\section{Impact}

The practice problem was that the organization had a good treatment process for patients developing severe sepsis, but there was no way to prevent them from developing severe sepsis. The practice change was to introduce an early Severe Sepsis Identification tool to reduce the number of patients developing severe sepsis. With the introduction of the tool, the rate of severe sepsis was reduced by $37 \%$. Timely notification of the change in patients' condition according to the organization's SOP was also improved by $24 \%$ with the introduction of the tool. The sepsis tool also reduced the length of hospital stay from 8.8 days to 4.1 days, which reduced hospitalization costs. The tool needs to be used consistently to maintain the decreased rate of severe sepsis. The sepsis coordinator will follow up on the tool to ensure consistency and conduct ongoing evaluation of the use of the new hires' tool and education using the protocol that has been developed. The sepsis coordinator will keep track of sepsis' rate in the organization and ensure that the staff is consistently using the tool. The sepsis coordinator will also ensure that this tool will be part of new hires' education to create awareness.

The future implications for the project could include adopting this tool within other medical centers of the organization. Once this tool is seen as a success at this medical center, it can be recommended to the other medical centers based on the project's success and the reduction in sepsis rate at the hospital. One of the limitations of this project was the inability to educate all nurses due to the COVID situation. Only the staff able to attend the meetings via 
Microsoft TEAMS was educated. The sepsis coordinator was able to educate the rest of the staff who could not attend the staff meetings. Another limitation was the sample size and the period of implementation. It is unclear if the results would be different with a larger sample over a more extended period.

\section{Plans for Dissemination}

Once the implementation was completed, and results were evaluated, the next step was sharing the results with the organization. The results were presented to the stakeholders, including the front-line nurses, in a PowerPoint presentation. The nurses were made aware of the importance of early identification of sepsis, including any challenges faced. Those present at the presentation included the preceptor, who is the inpatient clinical director, chief nursing officer, the director of education, the informaticist, and the sepsis coordinator. The pre- and postimplementation results were presented in a bar graph to the group. It was also discussed at the meeting that the findings would be shared with the infection control committee at the next meeting, by the sepsis coordinator.

The project's goal was to implement a sepsis identification tool to identify patients before they develop severe sepsis. As this project is successful in reducing the rate of severe sepsis at the organizational level, it can be disseminated to the organization's regional level, and more medical centers could be involved in implementing this tool. The project will be archived at the University of Saint Augustine for Health Sciences Library, Scholarship and Open Access Repository (SOAR), and the Virginia Henderson Library. At the peer level, the presentation could be posted on the organization's nursing pathways website for peer review and specific recommendations to the project. 
At the national level, the results are planned to be presented at the American Nursing Informatics Association (ANIA), where the importance of integrating the tool on EMR can be discussed. This organization was selected, as the DNP student is a member of this organization. The manuscript can be published in the Journal of Informatics Nursing (JIN), which is a publication of ANIA. Assessment of SIRS criteria is not standard practice currently but disseminating the results to many will eventually help make this tool a standard practice for nurses.

\section{Conclusion}

This project's primary goal was to implement a nurse-driven tool for early identification of sepsis to identify patients developing severe shock or going into septic shock. Studies have shown how sepsis was a significant burden and the most expensive reason for hospitalization (Gyang et al., 2016). A simple screening tool will help to identify sepsis early. If screening was not done, the chances were that the patients who would have benefited from the interventions were missed (Ruhumuliza et al., 2018)

In summary an organizational needs assessment was conducted using the SWOT analysis tool and it was identified that severe sepsis could be identified early to reduce morbidity, mortality, and hospital costs. Extensive literature review showed that a nurse driven tool could reduce the rate of severe sepsis. The Stetler model along with Lewin's change theory guided this EBP project. Thorough synthesis of literature was done, and practice recommendations identified. An implementation plan with a timeline and budget were developed. Results of the project were evaluated, and the impact of the project discussed. The project results were disseminated with further plans for sustainability. The expected outcome of early identification of severe sepsis was achieved by the reduction in the rate of severe sepsis. 


\section{References}

Adom, D., Joe, A.-A., \& Hussein, E. K. (2018). Theoretical and conceptual framework: Mandatory ingredients of a quality research . International Journal of Scientific Research, 7(1), 438-441. https://www.doi.org/10.36106/ijsr

American Association of Critical-Care Nurses. (2019). Nurses on the front line of sepsis. https://www.aacn.org/clinical-resources/sepsis

Amland, R. C., \& Hahn-Cover, K. E. (2019). Clinical decision support for early recognition of sepsis. American Journal of Medical Quality, 34(5), 494-501. https://doi.org/10.1177\%2F1062860619873225

Blayney, D. W. (2008). Strengths, weaknesses, opportunities, and threats. Journal of Oncology Practice, 4(2), 53. https://dx.doi.org/10.1200\%2FJOP.0820501

Camargo, F. C., Iwamoto, H. H., Galvao, C. M., Monteiro, D. A., Goulart, M. B., \& Garcia, L. A. (2017). Models for the implementation of evidence-based practice in hospital based nursing: A narrative review. Texto contexto-enferm, 26(4), e2070017. https://doi.org/10.1590/0104-07072017002070017

Chakraborty, R. K., \& Burns, B. (2020). Systemic inflammatory response syndrome. StatPearls Publishing.

Churpek, M. M., Zadravecz, F. J., Winslow, C., Howell, M. D., \& Edelson, D. P. (2015). Incidence and prognostic value of the systemic inflammatory response syndrome and organ dysfunction in ward patients. American Journal of Respiratory and Critical Care Medicine, 192(8), 958-964. https://doi.org/10.1164/rccm.201502-0275oc

Drahnak, D. M., Hravnak, M., Ren, D., Haines, A. J., \& Tuite, P. (2016). Scripting nurse communication to improve sepsis care. MEDSURG Nursing, 25(4), 233-239. 
Gyang, E., Shieh, L., Forsey, L., \& Maggio, P. (2016). A nurse-driven screening tool for the early identification of sepsis in an intermediate care unit setting. Journal of Hospital Medicine, 10(2), 97-103. https://dx.doi.org/10.1002\%2Fjhm.2291

Hospital Quality Institute. (2017). Sepsis in California. http://www.hqinstitute.org/sites/main/files/file-attachments/hqi_sepsis_final_aug2017.pdf

John Hopkins Medicine. (n.d.). John Hopkins evidence-based practice. Appendix C guide. https://www.hopkinsmedicine.org/evidence-basedpractice/_docs/appendix_c_evidence_level_quality_guide.pdf

Jones, S. L., Ashton, C. M., Kiehne, L., Masud, F., Shirkey, B. A., \& Wray, N. P. (2015). Reductions in sepsis mortality and costs after design and implementation of a nurse-based early recognition and response program. The Joint Commission Journal on Quality Patient Safety, 41(11), 483-491. https://doi.org/10.1016/s1553-7250(15)41063-3

Jung, A. D., Baker, J., Droege, C. A., Nomellini, V., Johannigman, J., Holcomb, J. B., Goodman, M. D., \& Pritts, T. A. (2018). Sooner is better: Use of a real-time automated bedside dashboard improves sepsis care. The Journal of Surgical Research, 231, 373-379. https://doi.org/10.1016/j.jss.2018.05.078

Keele, R. (2012). Implementing evidence-based nursing practice: An overview. Jones \& Barlett Learning .

Lewin, K. (1951). Field theory in social science. (1 ${ }^{\text {st }}$ ed.). New York Harper. https://archive.org/details/fieldtheoryinsoc0000lewi

Moher, D., Liberati, A., Tetzlaff, J., \& Altman, D. G. (2009). Preferred Reporting Items for Systematic Reviews and MetaAnalyses: The PRISMA Statement. PLoS Med 6(7): e1000097. https://doi.org/10.1371/journal.pmed.1000097 
Oregon Health and Science University. (2020). Evidence based practice toolkit for nursing. https://libguides.ohsu.edu/ebptoolkit/levelsofevidence

O’Shaughnessy, J., Grzelak, M., Dontsova, A., \& Braun-Alfana, I. (2017). Early sepsis identification. MEDSURG Nursing , 26(4), 248-252.

Ruhumuliza, C., Popkin, L., \& Sprague, A. (2018). Sepsis screening and nurse driven protocols. Sepsis Coordinator Network: https://www.sepsiscoordinatornetwork.org/wpcontent/uploads/2018/11/Sepsis-Screening-Webinar-v3A-slides.pdf

Sepsis Alliance. (2018). Sepsis fact sheet. https://www.sepsis.org/wpcontent/uploads/2017/05/Sepsis-Fact-Sheet-2018.pdf

Song, J. W., \& Chung, K. C. (2010). Observational studies: Cohort and case-control studies. Plastic Reconstructive Surgery, 126(6), 2234-2242. doi: 10.1097/PRS.0b013e3181f44abc.

Stetler, C. B. (2001). Updating the Stetler model of research utilization to facilitate evidencebased practice. Nursing Outlook, 49(6), 272-279. https://doi.org/10.1067/mno.2001.120517

Torsvik, M., Gustad, L. T., Mehl, A., Bangstad, I. L., Vinje, L. J., Damas, J. K., \& Solligard, E. (2016). Early identification of sepsis in hospital inpatients by ward nurses increases 30day survival. Critical Care, 20(244), https://doi.org/10.1186/s13054-016-1423-1.

Umscheid, C. A., Betesh, J., VanZandbergen, C., Hanish, A., Tait, G., Mark, M. E., French, B., \& Fuchs, B. D. (2015). Development, implementation and impact of an automated early warning and response system for sepsis. Journal of Hospital Medicine, 10(1), 26-31. https://doi.org/10.1002/jhm.2259 
Wawrose, R., Baraniuk, M., Standiford, L., Wade, C., Holcomb, J., \& Moore, L. (2015). Comparison of sepsis screeing tools' ability to detect sepsis accurately. Surgical Infections, 17(5), 525-529. https://doi.org/10.1089/sur.2015.069 


\section{Appendix A}

\section{Table A1}

\section{Budget}

\begin{tabular}{|c|c|c|c|}
\hline Expense & & Revenue & Results \\
\hline Direct & & $\begin{array}{l}\text { Hospital Length of Stay for } \\
\text { septic } \\
\text { patients (in days) }\end{array}$ & 4.4 days \\
\hline \multirow[t]{6}{*}{$\begin{array}{l}\text { Salary and benefits } \\
\text { Education of RNs x2 hours x } \\
\text { 630RN @ \$72.44 }\end{array}$} & $\$ 91,274.40$ & $\begin{array}{l}\text { Hospital length of stay for } \\
\text { severe/septic shock patient (in } \\
\text { days) }\end{array}$ & 8.1 days \\
\hline & & $\begin{array}{l}\text { Number of days saved by } \\
\text { preventing severe shock } 8.1-4.4 \\
\text { (in days) }\end{array}$ & 3.7 days \\
\hline & & $\begin{array}{l}\text { Average cost of hospital stays } \\
\text { per day }\end{array}$ & $\$ 9800.00$ \\
\hline & & $\begin{array}{l}\text { Amount of dollars saved due to } \\
\text { reduced hospital stay per } \\
\text { patient }\end{array}$ & $\$ 36,260.00$ \\
\hline & & $\begin{array}{l}\text { Estimated number of patients } \\
\text { per year going into } \\
\text { severe/septic shock }\end{array}$ & 200 \\
\hline & & $\begin{array}{l}\text { Estimated amount of dollars } \\
\text { saved }\end{array}$ & $\$ .7,252,000.00$ \\
\hline Total Expenses & $\$ 91,274.40$ & Total Revenue (estimated) & $\$ 7,252,000.00$ \\
\hline \multicolumn{3}{|l|}{ Net Balance } & $\$ 7,160726.00$ \\
\hline
\end{tabular}




\section{Figure A1}

\section{PRISMA Early Identification of Sepsis}

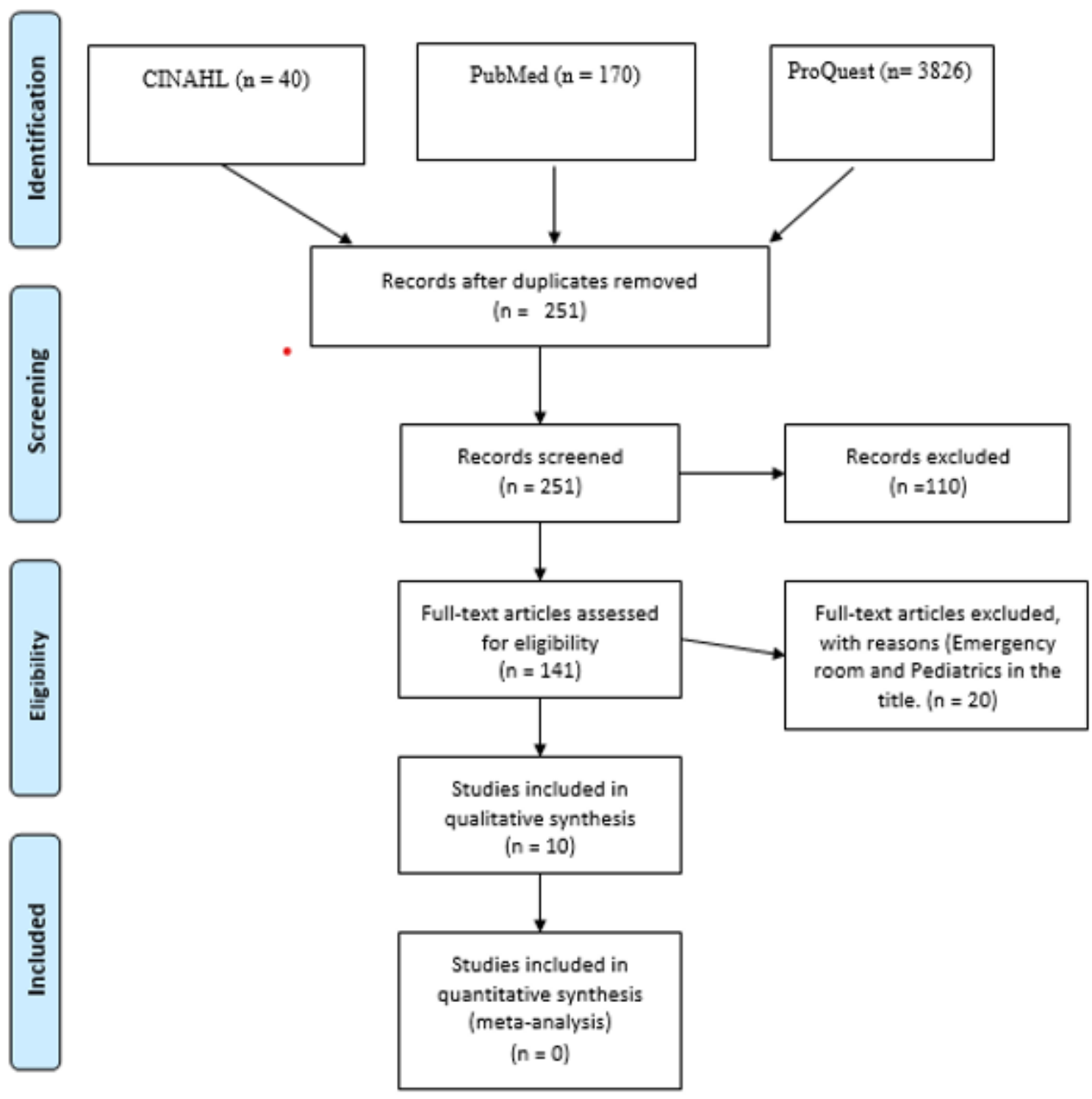

From: "Preferred Reporting Items for Systematic Reviews and MetaAnalyses: The PRISMA

Statement,” by D. Moher, A. Liberati, J. Tetzlaff \& D.G. Altman, 2009, Annals of Internal

Medicine, 151(4), p. 267 (http://dx.doi.org/10.7326/0003-4819-151-4-200908180-00135).

Copyright 2009 by The American College of Physicians. 


\section{Figure A2}

\section{Severe Sepsis Tool}
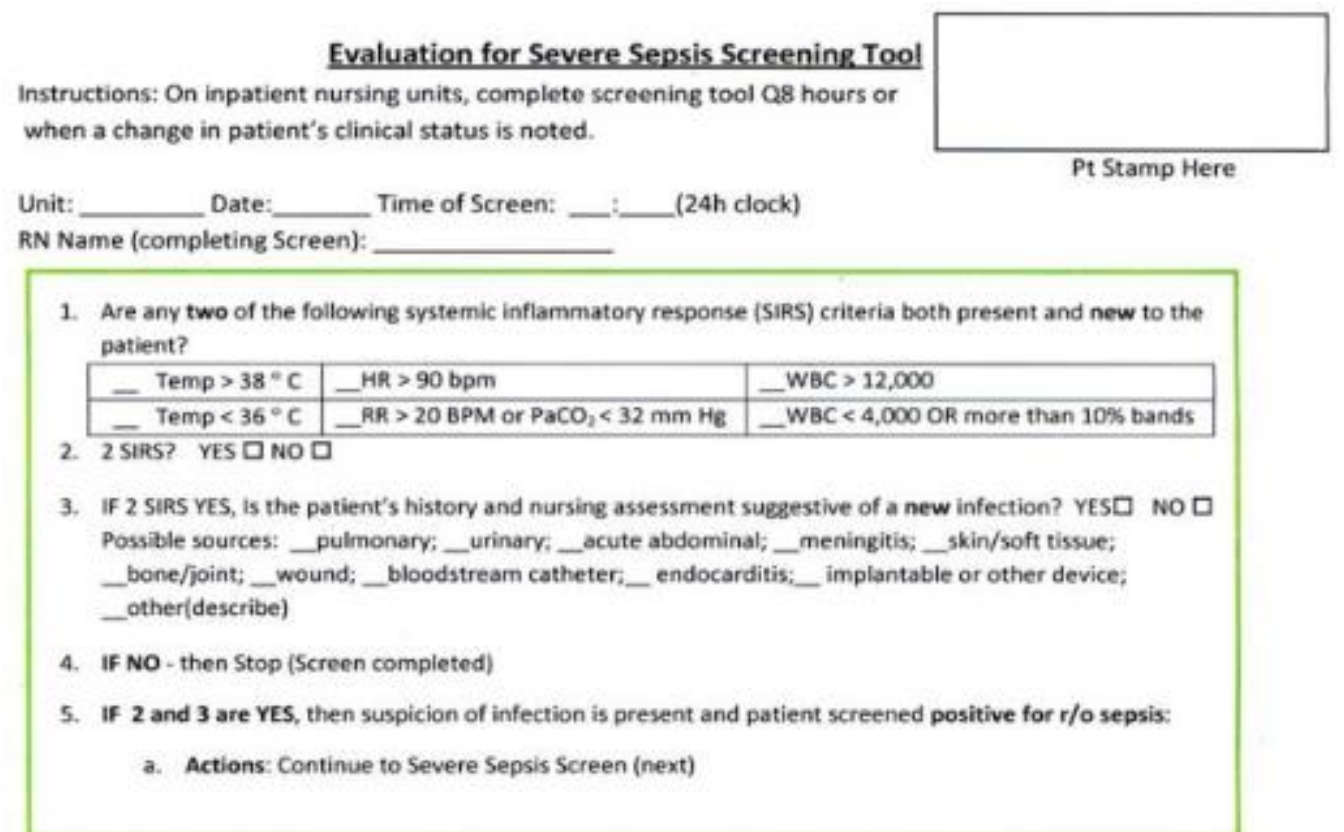

6. Are ANY of the following organ dysfunction criteria present that are not considered to be chronic conditions?

\begin{tabular}{|c|c|c|c|c|c|}
\hline 므 & $\begin{array}{l}\text { Neurological: Subtle or overt } \\
\text { change in mental status }\end{array}$ & 口 & $\begin{array}{l}\text { Metabolic: Serum } \\
\text { lactate }>2.0 \mathrm{mmol} / \mathrm{L}\end{array}$ & $D$ & $\begin{array}{l}\text { Pulmonary: } \mathrm{RR}>20 \mathrm{OR} \uparrow \mathrm{O} 2 \text { to } \\
\text { maintain } \mathrm{SpO}>90 \%\end{array}$ \\
\hline : & $\begin{array}{l}\text { Cardiac: } \\
\text { SBP }<90 \mathrm{mmHg} \\
\text { MAP }<65 \mathrm{mmHg} \\
>40 \mathrm{mmHg} \text { decrease in SaP } \\
\text { from patient's baseline } \\
\text { Capillary refil }>3 \text { seconds }\end{array}$ & • & $\begin{array}{l}\text { Renal: } \\
\text { UO }<.5 \mathrm{~mL} / \mathrm{kg} / \mathrm{hr} \text { for } 2 \\
\text { hrs (or }<30 \mathrm{ml} \text { per hr for } \\
2 \text { hrs) } \\
\text { Serum creatinine } \\
\text { increased by } 0.3 \mathrm{gm} / \mathrm{dl} \\
\text { in past } 48 \mathrm{hrs}\end{array}$ & D & $\begin{array}{l}\text { GI: Absent bowel sounds } \\
\text { (except recent post op pt) }\end{array}$ \\
\hline D & $\begin{array}{l}\text { Hematologic: Platelet count } \\
<100 \mathrm{k}\end{array}$ & 口 & $\begin{array}{l}\text { Heme/tiver: INR }>1.5 \\
\text { or a PTT > } 60 \text { secs }\end{array}$ & 0 & $\begin{array}{l}\text { Hyperbilirubinemia: Total } \\
\text { bilirubin }>4 \mathrm{mg} / \mathrm{d}\end{array}$ \\
\hline
\end{tabular}

7. If NO $\square$ then Call MD to inform of Positive 'sepsis' screen, implement Sepsis guidelines and continue to assess for severe sepsis.

8. IF YES $\square$ then patient screens positive for SEVERE Sepsis and severe sepsis guidelines should be initiated.

Call MD, Provide SBAR, Implement Severe
Sepsis Management Guidelines

From: "A nurse driven screening tool for the early identification of sepsis in an intermediate care unit setting,” by E. Gyang, L.Shieh, L. Forsey, , \& P. Maggio, 2016, Journal of Hospital Medicine 10(2), 97-103 (https://dx.doi.org/10.1002\%2Fjhm.2291). Copyright 2018 by Lynn Forsey. 


\section{Appendix B}

\section{Permission Letter}

From: Lisa Shieh <|shieh@stanford.edu>

Sent: Wednesday, June 3, 2020 1:49:39 PM

To: Ruth Biju <r.biju@@usa.edu>

Subject: Re: Permission to use sepsis screening tool

Yes of course!

Good luck and thanks for asking

Lisa

From: Ruth Biju <r.biju@usa.edu>

Date: Tuesday, June 2, 2020 at 11:00 PM

To: Lisa Shieh <Ishieh@stanford.edu>

Subject: Permission to use sepsis screening tool

Hello Dr. Shieh,

My name is Ruth Biju and I am a student of the Doctor of Nursing Program at the University of Saint Augustine. My dissertation is about developing a tool for the early identification of sepsis. I came across your article A Nurse-Driven Screening Tool for the Early Identification of Sepsis in an Intermediate Care Unit Setting. This article has a screening tool that I would love to use for my DNP project, and I request your permission to be able to use that. It is not for research purposes, but this tool will be utilized at the organization I intend to do my DNP project. I request your permission to use the tool. Please let me know if you have any questions. Thank you

Ruth Biju.BSN, RN 


\section{Appendix C}

\section{John Hopkins Nursing Evidence Based Practice Model}

\begin{tabular}{|c|c|}
\hline Evidence Level & Quality Rating \\
\hline $\begin{array}{ll}\text { Level I } \\
\text { - Randomized Controlled Trials (RCT) } \\
\text { - Experimental Studies } \\
\text { - Systematic Reviews (SR) of RCTs } \\
\quad \text { with or without meat-analysis } \\
\end{array}$ & $\begin{array}{l}\text { A -High Quality } \\
\text { Officially sponsored material by } \\
\text { government organization, professional, } \\
\text { private, or public organization, } \\
\text { developed or revised within the last }\end{array}$ \\
\hline $\begin{array}{l}\text { Level II } \\
\text { - SR with RCT and Quasi- } \\
\text { experimental } \\
\text { - } \\
\text { Quasi-experimental with or without } \\
\text { - } \text { Quasi-experimental } \\
\end{array}$ & $\begin{array}{l}\text { five years, clear aims and objectives, } \\
\text { consistent results across multiple } \\
\text { settings, definite conclusions with } \\
\text { scientific rationales. } \\
\text { B- Good Quality } \\
\text { Officially sponsored by government }\end{array}$ \\
\hline $\begin{array}{l}\text { Level III } \\
\text { - Non-Experimental Studies } \\
\text { - SR with RCTs, } \\
\text { - Quasi-experimental and Non- } \\
\text { experimental studies with or without } \\
\text { meta-analysis } \\
\text { - Qualitative studies } \\
\text { - SR with or without meta-synthesis } \\
\end{array}$ & $\begin{array}{l}\text { agency or a professional, public or } \\
\text { private organization, written or revised } \\
\text { in the last five years, consistent results, } \\
\text { clear aims and objectives, some } \\
\text { reference to scientific evidence, } \\
\text { reasonably consistent } \\
\text { recommendations, relatively definitive } \\
\text { conclusions, credible expertise with } \\
\text { materials with logical arguments }\end{array}$ \\
\hline $\begin{array}{l}\text { Level IV } \\
\text { - Clinical practice guidelines } \\
\text { - Consensus panels }\end{array}$ & $\begin{array}{l}\text { C- Low Quality } \\
\text { Poorly defined, not sponsored by an } \\
\text { official organization or agency, }\end{array}$ \\
\hline $\begin{array}{l}\text { Level V } \\
\text { - Literature reviews } \\
\text { - Case reports } \\
\text { - Program or financial evaluation } \\
\text { - Opinions of experts }\end{array}$ & $\begin{array}{l}\text { contained insufficient evidence and } \\
\text { insufficient results, limited literature } \\
\text { search strategies, conclusions } \\
\text { inconclusive, not revised in the last five } \\
\text { years, inconsistent results, aims and } \\
\text { objectives unclear, no } \\
\text { recommendations, expertise not } \\
\text { discernable. }\end{array}$ \\
\hline
\end{tabular}


From: "John Hopkins evidence-based practice. Appendix C guide," by John Hopkins Medicine, n.d., https://www.hopkinsmedicine.org/evidence-based-

practice/_docs/appendix_c_evidence_level_quality_guide.pdf. Copyright by The John Hopkins Hospital/John Hopkins University. 


\section{Appendix D}

Summary of Primary Research Evidence

\begin{tabular}{|c|c|c|c|c|c|c|}
\hline Citation & $\begin{array}{l}\text { Design, Level } \\
\text { Quality Grade }\end{array}$ & $\begin{array}{c}\text { Sample } \\
\text { Sample size }\end{array}$ & $\begin{array}{c}\text { Intervention } \\
\text { Comparison } \\
\text { (Definitions should include any } \\
\text { specific research tools used along } \\
\text { with reliability } \& \text { validity) }\end{array}$ & $\begin{array}{l}\text { Theoretical } \\
\text { Foundation }\end{array}$ & $\begin{array}{l}\text { Outcome } \\
\text { Definition }\end{array}$ & $\begin{array}{c}\text { Usefulness } \\
\text { Results } \\
\text { Key Findings }\end{array}$ \\
\hline $\begin{array}{l}\text { Amland \& Hahn- } \\
\text { Cover (2019) }\end{array}$ & $\begin{array}{l}\text { Multicenter } \\
\text { Retrospective } \\
\text { Cohort design } \\
\text { Level } 2 \\
\text { Grade A }\end{array}$ & $\begin{array}{l}\text { A convenience } \\
\text { sample including } \\
\text { Cohorts from } 5 \\
\text { different medical } \\
\text { centers including } \\
\text { Level } 1 \& 2 \text { trauma } \\
\text { center, women's } \\
\text { and children's } \\
\text { hospital and } 2 \\
\text { community } \\
\text { hospitals } \\
\text { N=6200 }\end{array}$ & $\begin{array}{l}\text { Patients with SIRS or severe SIRS } \\
\text { criteria were captured from the EHR. } \\
\text { If criteria for SIRS or severe SIRS } \\
\text { align, an alert is activated. Charts } \\
\text { that were flagged were manually } \\
\text { examined for relationship and timing } \\
\text { between alerts and clinical indication } \\
\text { of SIRS. Some activated alerts may } \\
\text { be interpreted as false positives and } \\
\text { accuracy can be improved by } \\
\text { conducting different tests like } \\
\text { cultures, serology, lactic acid. Sepsis } \\
\text { CDS promotes early recognition } \\
\text { with a degree of accuracy. A } \\
\text { confusion matrix was applied to } \\
\text { report correct classification rate, } \\
\text { sepsis prevalence rate, sensitivity } \\
\text { and specificity, positive and negative } \\
\text { predictive value and metrics for } \\
\text { sepsis CDS }\end{array}$ & $\begin{array}{l}\text { Clinometric } \\
\text { Analytic } \\
\text { framework }\end{array}$ & $\begin{array}{c}\text { The sepsis CDS } \\
\text { enables } \\
\text { providers to } \\
\text { speed up } \\
\text { diagnosis and } \\
\text { therapeutic } \\
\text { interventions to } \\
\text { reverse sepsis } \\
\text { syndrome and } \\
\text { avoid } \\
\text { complications }\end{array}$ & $\begin{array}{c}\text { Sepsis CDS } \\
\text { integrated into EHR } \\
\text { is effective toward } \\
\text { early recognition of } \\
\text { sepsis in a hospital } \\
\text { setting }\end{array}$ \\
\hline
\end{tabular}




\begin{tabular}{|c|c|c|c|c|c|c|}
\hline $\begin{array}{l}\text { Churpek et al., } \\
(2015) \text {. }\end{array}$ & $\begin{array}{l}\text { Observation } \\
\text { design } \\
\text { Level } 2 \\
\text { Grade C }\end{array}$ & $\begin{array}{l}\text { A convenience } \\
\text { sample of } \\
\text { hospitalized ward } \\
\text { patients from five } \\
\text { hospitals } \\
\mathrm{N}=269,951\end{array}$ & $\begin{array}{l}\text { The association between each organ } \\
\text { dysfunction and mortality, the } \\
\text { number of simultaneous organ } \\
\text { dysfunction, and the change to time } \\
\text { over each organ dysfunction over the } \\
\text { first } 24 \text { hours were compared. } \\
\text { Sensitivity analysis was performed } \\
\text { where only vital signs were } \\
\text { measured and used to calculate if } \\
\text { patient had SIRS. Characteristics } \\
\text { were compared using t-tests, chi- } \\
\text { square tests and Wilcoxon rank sum } \\
\text { tests. }\end{array}$ & None & $\begin{array}{l}\text { Proportion of } \\
\text { patients who met } \\
\text { SIRS criteria } \\
\text { during their stay at } \\
\text { the hospital } \\
\text { increased from } \\
15 \% \text { on admission } \\
\text { to more than } 70 \% \\
\text { remaining in the } \\
\text { ward for } 7 \text { days }\end{array}$ & $\begin{array}{l}\text { Half of the } \\
\text { patients } \\
\text { hospitalized } \\
\text { developed } \\
\text { SIRS once } \\
\text { during their } \\
\text { hospital stay } \\
\text { and screening } \\
\text { patients using } \\
\text { SIRS criteria } \\
\text { for early } \\
\text { identification } \\
\text { of sepsis is } \\
\text { time } \\
\text { consuming and } \\
\text { impractical }\end{array}$ \\
\hline $\begin{array}{l}\text { Drahnak et al., } \\
\text { (2016). }\end{array}$ & $\begin{array}{l}\text { Cohort Design } \\
\text { Level I Grade } \\
\text { A }\end{array}$ & $\begin{array}{l}\text { Level I trauma } \\
\text { hospital Nurses } \\
\mathrm{N}=681\end{array}$ & $\begin{array}{l}\text { A preintervention retrospective chart } \\
\text { review showed that nurses were not } \\
\text { completing the sepsis screen } \\
\text { consistently. Nurse administrators } \\
\text { called to improve patient care and } \\
\text { nurses` involvement in the screening } \\
\text { of sepsis process. Pre-post survey } \\
\text { was used to assess the impact of } \\
\text { education on nurses` knowledge and } \\
\text { chart audits were done to determine } \\
\text { adherence to the sepsis screening } \\
\text { tool. Wilcoxon Signed-Rank Test } \\
\text { was used to evaluate the Likert scale } \\
\text { items. After education the nurses } \\
\text { rated themselves as more } \\
\text { knowledgeable about sepsis p was } \\
<0.0001 . \text { test scores increased by } \\
7.28 \%-63.5 \% \text { in the post test. A } \\
\text { statistical significance in improved } \\
\text { sepsis screening using chi-square test } \\
\text { was p<0.0001. }\end{array}$ & None & $\begin{array}{l}\text { Chart audits done } \\
\text { post education } \\
\text { showed a decrease } \\
\text { in the number of } \\
\text { patients for whom } \\
\text { sepsis screening } \\
\text { was never done. } \\
\text { The rate of patients } \\
\text { who were never } \\
\text { screened reduced } \\
\text { from } 40.6 \% \text { to } \\
8.9 \%\end{array}$ & $\begin{array}{l}\text { With continued } \\
\text { vigilance and } \\
\text { support from } \\
\text { administration } \\
\text { can improve } \\
\text { nurses } \\
\text { adherence to } \\
\text { sepsis } \\
\text { screening tests } \\
\text { and provide } \\
\text { optimal patient } \\
\text { outcomes. } \\
\text { providing } \\
\text { nurses with the } \\
\text { appropriate } \\
\text { tool forms a } \\
\text { strong } \\
\text { foundation for } \\
\text { sepsis } \\
\text { treatment } \\
\text { programs. }\end{array}$ \\
\hline
\end{tabular}




\begin{tabular}{|c|c|c|c|c|c|c|}
\hline $\begin{array}{l}\text { Gyang et al., } \\
\text { (2016). }\end{array}$ & $\begin{array}{l}\text { Observational } \\
\text { design Level I } \\
\text { Grade A }\end{array}$ & $\begin{array}{l}\text { A convenience } \\
\text { sample of patients } \\
\text { admitted to } \\
\text { medical-surgical } \\
\text { intermediate care } \\
\text { unit of an academic } \\
\text { medical center } \\
\mathrm{N}=245\end{array}$ & $\begin{array}{l}\text { Intervention included screening } \\
\text { patients for SIRS criteria for sepsis } \\
\text { and if they were found positive for } \\
\text { sepsis or severe sepsis the nurses } \\
\text { were instructed to call primary care } \\
\text { team to initiate hospital wide sepsis } \\
\text { guidelines. The specificity and } \\
\text { sensitivity of the screening tool was } \\
\text { determined by identifying false- } \\
\text { positive, true-positive, false negative } \\
\text { and true-negative results. Screening } \\
\text { tool had a specificity of } 91.9 \% \text { and } \\
\text { sensitivity of } 95.5 \% \text { and accuracy } \\
\text { was } 92 \%\end{array}$ & None & $\begin{array}{l}39 \text { patients were } \\
\text { found positive for } \\
\text { sepsis out of which } \\
20 \text { were classified } \\
\text { as sepsis and } 19 \\
\text { with severe sepsis. } \\
\text { The proportion of } \\
\text { patients who } \\
\text { received sepsis } \\
\text { related actions } \\
\text { after testing } \\
\text { positive for sepsis } \\
\text { screening like } \\
\text { antibiotics, blood } \\
\text { cultures, lactate } \\
\text { measurement were } \\
\text { higher than those } \\
\text { with negative } \\
\text { screening. The } \\
\text { screening test was } \\
\text { conducted in three } \\
\text { tiers. The first tier } \\
\text { was based on SIRS } \\
\text { criteria and the } \\
\text { second tier was } \\
\text { looking for source } \\
\text { of infection and the } \\
\text { third being looking } \\
\text { for organ damage. } \\
\text { Education } \\
\text { component of the } \\
\text { nursing staff was } \\
\text { vital before starting } \\
\text { the screening } \\
\text { protocol. }\end{array}$ & $\begin{array}{l}\text { A screening for } \\
\text { sepsis by the } \\
\text { bedside nurse } \\
\text { using a tool } \\
\text { which is simple } \\
\text { can be used to } \\
\text { identify sepsis } \\
\text { early and lead } \\
\text { to timely } \\
\text { diagnostics and } \\
\text { treatment in an } \\
\text { intermediate } \\
\text { care setting for } \\
\text { both medical } \\
\text { and surgical } \\
\text { patients. }\end{array}$ \\
\hline
\end{tabular}




\begin{tabular}{|c|c|c|c|c|c|c|}
\hline Jones et al., (2015). & $\begin{array}{l}\text { Pre and Post } \\
\text { Intervention } \\
\text { Design } \\
\text { Level 1 } \\
\text { Grade B }\end{array}$ & $\begin{array}{l}\text { A convenience } \\
\text { sample of patients } \\
\text { at Houston } \\
\text { Methodist Hospital } \\
\text { (HMH) } \\
\mathrm{N}=9718\end{array}$ & $\begin{array}{l}\text { There were four components to } \\
\text { the intervention organizational } \\
\text { commitment, integration of a } \\
\text { sepsis screening tool into EHR, } \\
\text { creating screening and response } \\
\text { protocols, and education of } \\
\text { nurses. Screening was done twice } \\
\text { daily by the bedside nurse and } \\
\text { nurse practitioners started } \\
\text { definitive treatment. Inpatient } \\
\text { death rate during the pre- } \\
\text { implementation period and } \\
\text { implementation period with } \\
\text { confidence interval were } \\
\text { calculated using exact method. } \\
\text { The cost and utilization data were } \\
\text { also calculated using HMH's } \\
\text { database. }\end{array}$ & None & $\begin{array}{c}\text { The sepsis } \\
\text { associated inpatient } \\
\text { death rate was } \\
\text { significantly lower } \\
\text { than the pre } \\
\text { implementation } \\
\text { phase. Inpatient } \\
\text { care was also found } \\
\text { to be lower and } \\
\text { they were not offset } \\
\text { by comparable } \\
\text { increase in number } \\
\text { of survivors being } \\
\text { discharged to } \\
\text { higher level of care. }\end{array}$ & $\begin{array}{l}\text { This program is one } \\
\text { of the many } \\
\text { programs being } \\
\text { implemented in the } \\
\text { United States for } \\
\text { early detection of } \\
\text { sepsis and prompt } \\
\text { treatment. Further } \\
\text { testing is warranted } \\
\text { to check for } \\
\text { robustness and } \\
\text { exportability of } \\
\text { these programs. }\end{array}$ \\
\hline Jung et al., (2018). & $\begin{array}{l}\text { Pre-Post } \\
\text { intervention } \\
\text { design. } \\
\text { Level } 1 \text { Grade } \\
\text { B }\end{array}$ & $\begin{array}{l}\text { A convenience } \\
\text { sample of patients } \\
\text { admitted to SICU } \\
\text { at the University of } \\
\text { Cincinnati Medical } \\
\text { Center } \\
\mathrm{N}=232\end{array}$ & $\begin{array}{l}30 \text { patients were confirmed to } \\
\text { have sepsis and they were divided } \\
\text { into two groups. Pre group } \\
\text { included patients admitted to } \\
\text { SICU before the implementation } \\
\text { of Sepsis Screen Score and the } \\
\text { Post group included patients } \\
\text { admitted to SICU after the } \\
\text { implementation of the Sepsis } \\
\text { Screen score. Time to antibiotics } \\
\text { was calculated and recorded in } \\
\text { the EMR. Univariate analysis for } \\
\text { continuous variables was done } \\
\text { using student's t-test and } \\
\text { AVOVA. Statistical significance } \\
\text { was p<0.05 }\end{array}$ & None & $\begin{array}{l}\text { Twenty-three of the } \\
30 \text { patients were } \\
\text { admitted before the } \\
\text { implementation of } \\
\text { SSS and seven were } \\
\text { admitted after the } \\
\text { implementation. } \\
\text { Time to antibiotic } \\
\text { administration was } \\
\text { significantly shorter } \\
\text { in the post group } \\
\text { along with LOS. } \\
\text { There was no } \\
\text { difference in the } \\
\text { mortality rate } \\
\text { between the pre and } \\
\text { post group. }\end{array}$ & $\begin{array}{c}\text { Implementation of } \\
\text { SSS led to } \\
\text { decreased time } \\
\text { interval between } \\
\text { diagnosis of sepsis/ } \\
\text { shock, } \\
\text { administration of } \\
\text { antibiotics and thus } \\
\text { leading to } \\
\text { decreased ICU and } \\
\text { hospital stay. } \\
\text { Integrating clinical } \\
\text { decision support } \\
\text { can help providers } \\
\text { to adhere to } \\
\text { guidelines for } \\
\text { identification of } \\
\text { sepsis and it's } \\
\text { treatment and } \\
\text { improve quality of } \\
\text { care }\end{array}$ \\
\hline
\end{tabular}




\begin{tabular}{|c|c|c|c|c|c|c|}
\hline $\begin{array}{l}\text { O'Shaughnessy et } \\
\text { al., (2017). }\end{array}$ & $\begin{array}{l}\text { Cohort design } \\
\text { Level } 1 \text { Grade } \\
\text { A }\end{array}$ & $\begin{array}{l}\text { Patients of two } \\
\text { hospitals admitted } \\
\text { to medical surgical } \\
\text { ward with acute } \\
\text { and chronic } \\
\text { conditions } \\
\mathrm{N}=90\end{array}$ & $\begin{array}{l}\text { A retrospective chart review was } \\
\text { completed a month before project } \\
\text { was implemented. At hospital \#1, } \\
15 \text { cases of sepsis were identified } \\
\text { but only one patient had } \\
\text { documentation of provider } \\
\text { notification and that did not } \\
\text { happen till } 36 \text { hours after the } \\
\text { patient met the criteria. Hospital } \\
\text { \#2 had } 18 \text { cases of sepsis and in } \\
\text { four cases the provider was } \\
\text { notified within a time of } 182 \\
\text { minutes. Nurses were educated on } \\
\text { sepsis pathology, signs and } \\
\text { symptoms and use of sepsis } \\
\text { screening tool. The screening tool } \\
\text { was implemented, and nurses } \\
\text { were instructed to notify provider } \\
\text { of any positive sepsis screen and } \\
\text { notify RRT if there was acute } \\
\text { organ dysfunction. At the end of } \\
\text { the intervention period chart } \\
\text { audits were conducted and this } \\
\text { identified } 19 \text { cases of sepsis at } \\
\text { hospital } 1 \text { and } 31 \text { cases at hospital } \\
2 . \text { Pre and post-test of nurses } \\
\text { knowledge showed an increase of } \\
50 \% \text { at hospital } 1 \text { and } 53 \% \text { at } \\
\text { hospital } 2 . \text { Provider notification } \\
\text { by the nurses increased from } \\
6.7 \% \text { to } 84.2 \% \text { at hospital } 1 \text { and } \\
22.2 \% \text { to } 45.2 \% \text { at hospital } 2 . \text { The } \\
\text { time to notification was reduced } \\
\text { to an average of } 42 \text { minutes at } \\
\text { hospital } 1 \text { and } 138 \text { minutes at } \\
\text { hospital } 2 \text {. }\end{array}$ & $\begin{array}{l}\text { Seven-Phase } \\
\text { action cycle } \\
\text { of } \\
\text { knowledge } \\
\text { to action }\end{array}$ & $\begin{array}{l}\text { With the } \\
\text { implementation of } \\
\text { standardized } \\
\text { screening tools, } \\
\text { nurses can identify } \\
\text { sepsis. Nurses need } \\
\text { to be educated on } \\
\text { comprehension of } \\
\text { sepsis, } \\
\text { pathophysiology } \\
\text { and importance of } \\
\text { screening } \\
\text { parameters. } \\
\text { Subsequent } \\
\text { reinforcements of } \\
\text { the education must } \\
\text { be done. } \\
\text { Administrative } \\
\text { support and a local } \\
\text { sepsis champion } \\
\text { will help with } \\
\text { effective sepsis } \\
\text { screening. The } \\
\text { percentage of sepsis } \\
\text { cases reported to } \\
\text { providers increased } \\
\text { and decreased the } \\
\text { average time from } \\
\text { manifestation to } \\
\text { sepsis to } \\
\text { notification of } \\
\text { provider }\end{array}$ & $\begin{array}{c}\text { With nurse } \\
\text { education related to } \\
\text { sepsis and routine } \\
\text { sepsis screening, } \\
\text { early identification } \\
\text { of sepsis with } \\
\text { provider } \\
\text { notification and } \\
\text { decreased time to } \\
\text { notification can be } \\
\text { achieved. Nurses } \\
\text { need routine } \\
\text { education on the } \\
\text { escalation of } \\
\text { symptoms and } \\
\text { management of } \\
\text { sepsis. }\end{array}$ \\
\hline
\end{tabular}




\begin{tabular}{|c|c|c|c|c|c|c|}
\hline $\begin{array}{l}\text { Torsvik et al., } \\
\text { (2016). }\end{array}$ & $\begin{array}{l}\text { Cohort Design } \\
\text { Level } 1 \\
\text { Grade A }\end{array}$ & $\begin{array}{l}\text { A convenience } \\
\text { sample of patients } \\
\text { at a community } \\
\text { hospital in Mid- } \\
\text { Norway } \\
\mathrm{N}=881\end{array}$ & $\begin{array}{l}\text { A bundle with a flow chart for } \\
\text { sepsis identification, treatment } \\
\text { and physician response time a } \\
\text { SIRS and organ failure triage was } \\
\text { used to evaluate for sepsis. the } \\
\text { bundle also included training of } \\
\text { all nurses. Pre intervention group } \\
\text { included patients who were } \\
\text { positive for blood stream } \\
\text { infection (BSI) before the } \\
\text { implementation of the } \\
\text { intervention. Post intervention } \\
\text { group included patients with BSI } \\
\text { admitted after the implementation } \\
\text { of the intervention. McCabe score } \\
\text { was used to exclude patients who } \\
\text { were expected to die within one } \\
\text { month. Charlson Weighted } \\
\text { Comorbidity Index was classified } \\
\text { as low, medium or high } \\
\text { depending on the score. T test and } \\
\text { chi-square test were used to } \\
\text { compare patient base line data } \\
\text { and nurse's observation in the pre } \\
\text { and post intervention groups. }\end{array}$ & $\begin{array}{l}\text { Charlson } \\
\text { comorbidity } \\
\text { index model }\end{array}$ & $\begin{array}{l}\text { Nurses in the post } \\
\text { intervention period } \\
\text { got better at } \\
\text { monitoring of vital } \\
\text { signs including } \\
\text { respiratory rate. } \\
\text { SIRS criteria is } \\
\text { useful in the } \\
\text { identification of } \\
\text { infection and the } \\
\text { practitioner's } \\
\text { clinical assessments } \\
\text { should not lead to } \\
\text { delay in } \\
\text { investigation or } \\
\text { treatment of } \\
\text { infection. }\end{array}$ & $\begin{array}{l}\text { Flow chart alert, } \\
\text { sepsis specific } \\
\text { triage and treatment } \\
\text { system for patients } \\
\text { may lead to } \\
\text { increased survival } \\
\text { reduced occurrence } \\
\text { of severe } \\
\text { sepsis/shock and } \\
\text { shorter hospital } \\
\text { stay. }\end{array}$ \\
\hline
\end{tabular}




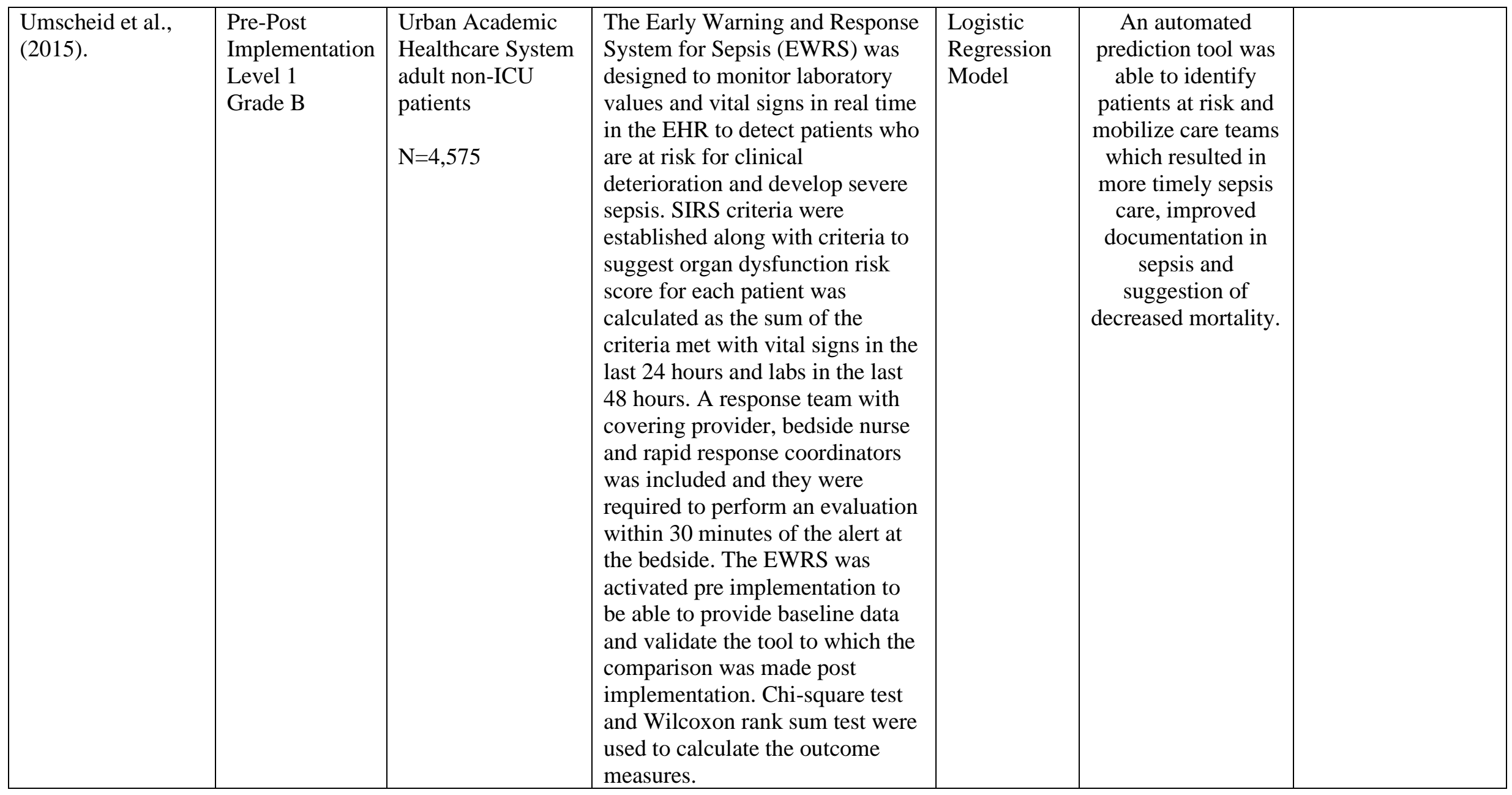




\begin{tabular}{|c|c|c|c|c|c|c|}
\hline $\begin{array}{l}\text { Wawrose et al., } \\
\text { (2015). }\end{array}$ & $\begin{array}{l}\text { Cohort design } \\
\text { Level } 1 \\
\text { Grade B }\end{array}$ & $\begin{array}{l}\text { A convenience } \\
\text { sample of patients } \\
\text { at Memorial } \\
\text { Hermann Hospital, } \\
\text { Texas } \\
\mathrm{N}=348\end{array}$ & $\begin{array}{l}\text { Two tools Sepsis Screening tool } \\
\text { (SSS)and St John's Screening } \\
\text { Sepsis Agent (SJSA) were used } \\
\text { on the same patient population. } \\
\text { The SSS was used twice a day on } \\
\text { the patients while the SJSA was } \\
\text { screened continuously via data } \\
\text { through HL7from the EMR which } \\
\text { included charting tools, vital } \\
\text { signs monitor and laboratory } \\
\text { tests. Sepsis definition as outlined } \\
\text { by ACCP/SCCM were used to } \\
\text { determine if patient developed } \\
\text { sepsis and the source of infection } \\
\text { was also recorded along with } \\
\text { culture data. The time stamp of } \\
\text { when patient reached sepsis was } \\
\text { also recorded. The sensitivity, } \\
\text { specificity of the negative } \\
\text { predictive value (NPV)and } \\
\text { positive predictive value } \\
\text { (PPV)for both SSS and SJSA } \\
\text { were calculated and compared. } \\
\text { Statistical significance was set at } \\
\text { p<0.05 and the differences in } \\
\text { sensitivities, PPVs and NPVs } \\
\text { were found to be statistically } \\
\text { significant. }\end{array}$ & None & $\begin{array}{l}\text { In the total of } 348 \\
\text { patients included in } \\
\text { the sample, } 47 \text { were } \\
\text { determined to be } \\
\text { septic. Of the } 47 \\
\text { patients } 35 \text { were } \\
\text { identified by S.S. } \\
\text { and only } 21 \\
\text { identified by } \\
\text { SJSA. } 23 \text { patients } \\
\text { identified by SSS } \\
\text { were not identified } \\
\text { by SJSA but only } \\
\text { nine patients with } \\
\text { sepsis identified by } \\
\text { SJSA were not } \\
\text { identified by SSS. }\end{array}$ & $\begin{array}{c}\text { The interpretation } \\
\text { suggests that SSS } \\
\text { can detect sepsis } \\
\text { accurately than } \\
\text { SJSA. It establishes } \\
\text { a basis for } \\
\text { utilization of the } \\
\text { SSS rather than the } \\
\text { SJSA. }\end{array}$ \\
\hline
\end{tabular}




\section{Appendix E}

\section{SWOT Analysis}

\section{STRENGTHS}

\section{WEAKNESSES}

\# Dedicated Sepsis Coordinator.

\# EPIC EHR making it easy for Data extraction.

\# Easy viewing of the tool because it is electronic.

* Interdisciplinary team approach.

* Availability of an existing tool for SIRS screening.

\# Existing treatment protocol at the organization for severe sepsis and septic shock.

\# Institution`s interest on creating a tool for some time.

\# Support from the organization.

\section{OPPORTUNITIES}

\section{THREATS}

* Improving rate for mortality and morbidity for septic patients

\# Education of staff on recognition and documentation of sepsis screening.

\# Reduction in hospital costs.

* If negative for sepsis per the screening tool, we can look for other diagnosis and treat patient accordingly.
* Resistance to change by staff.

\# False positive or negative results during screening.

\# False interpretation by staff
Increase workload for staff.

Increase in mortality and morbidity due to false negative results 


\section{Appendix F}

\section{Power Point for Sepsis tool Nurse Orientation}

\section{Early Identification of Sepsis Use of Sepsis Identification Tool}



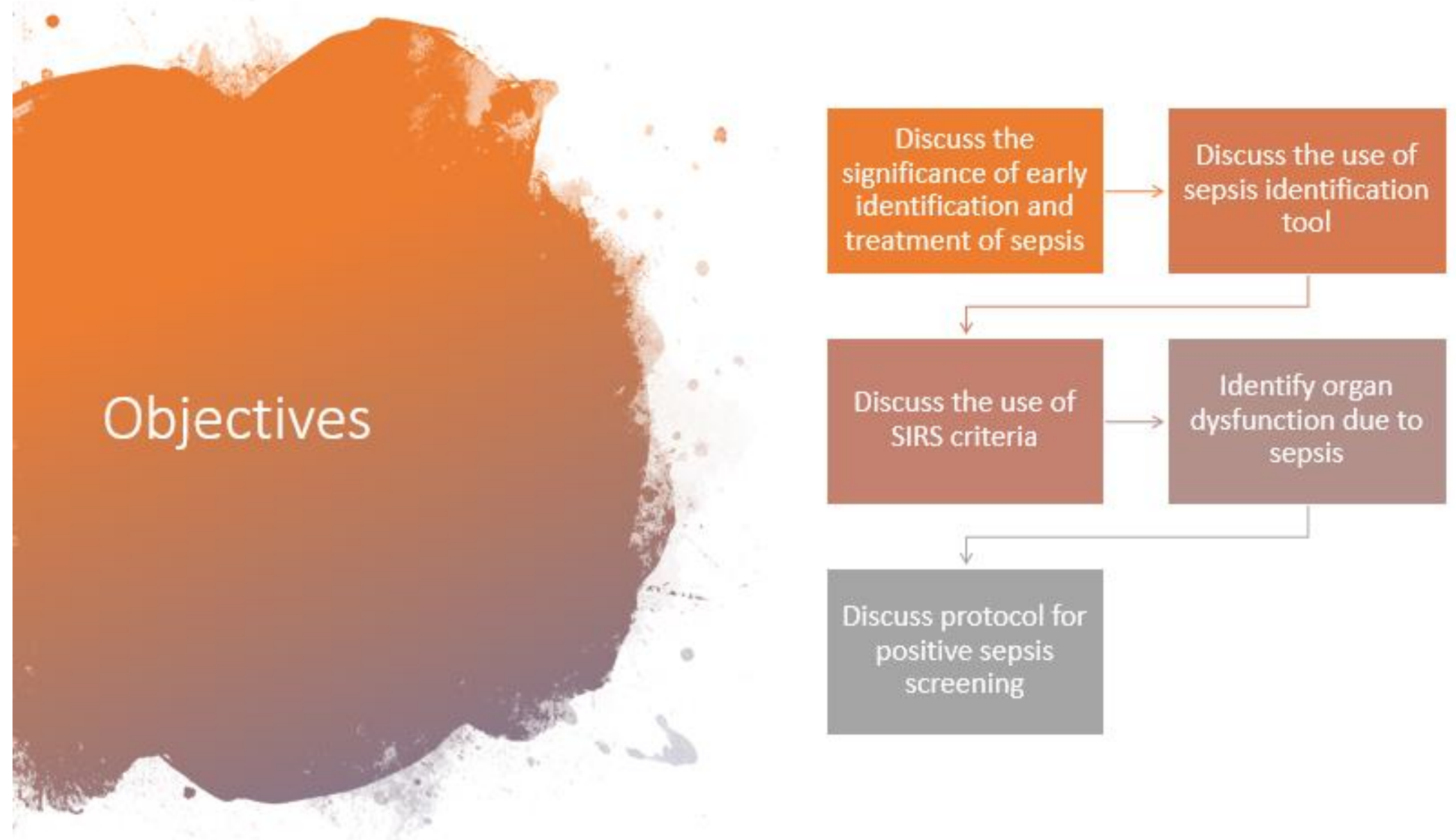


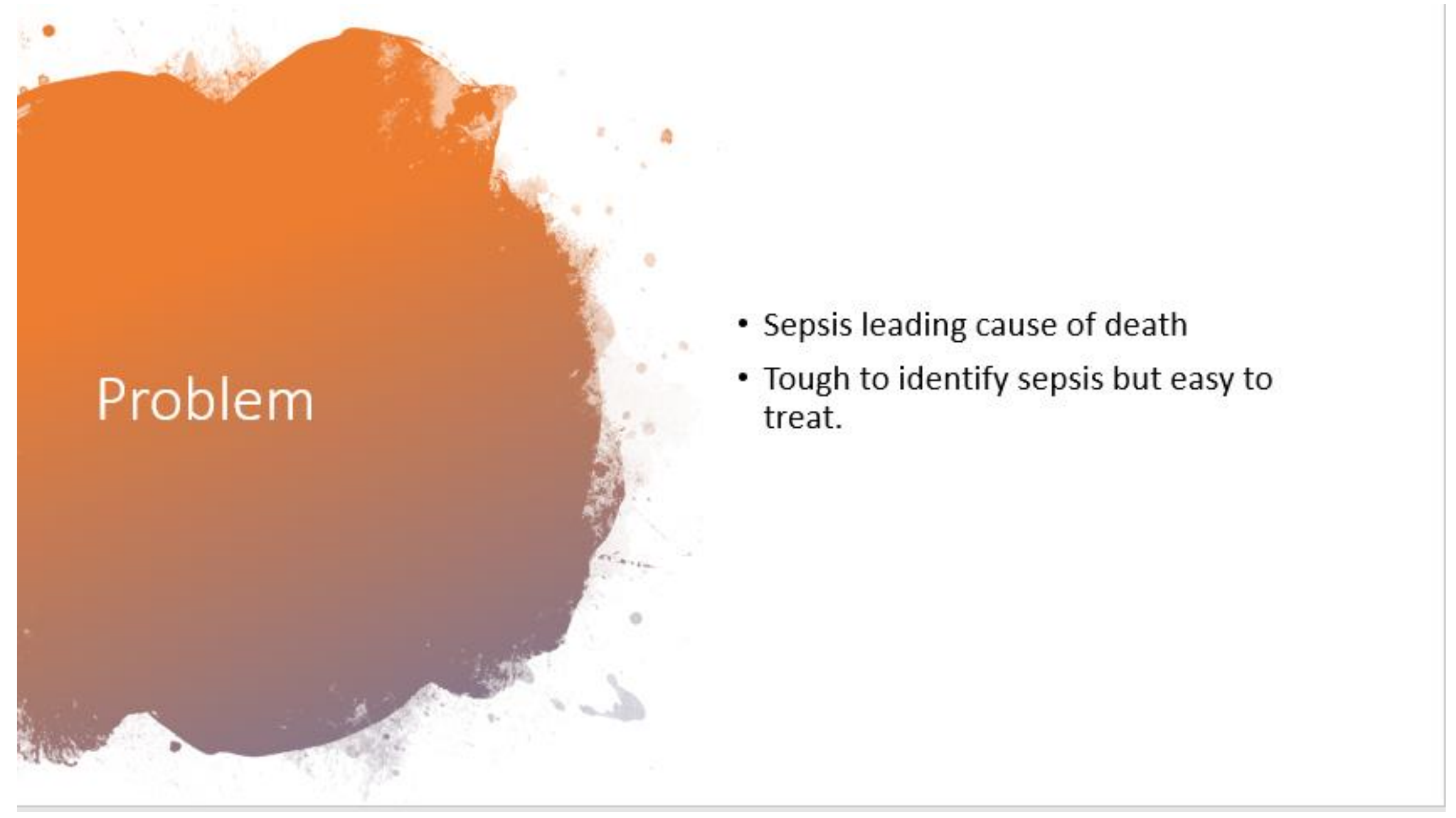




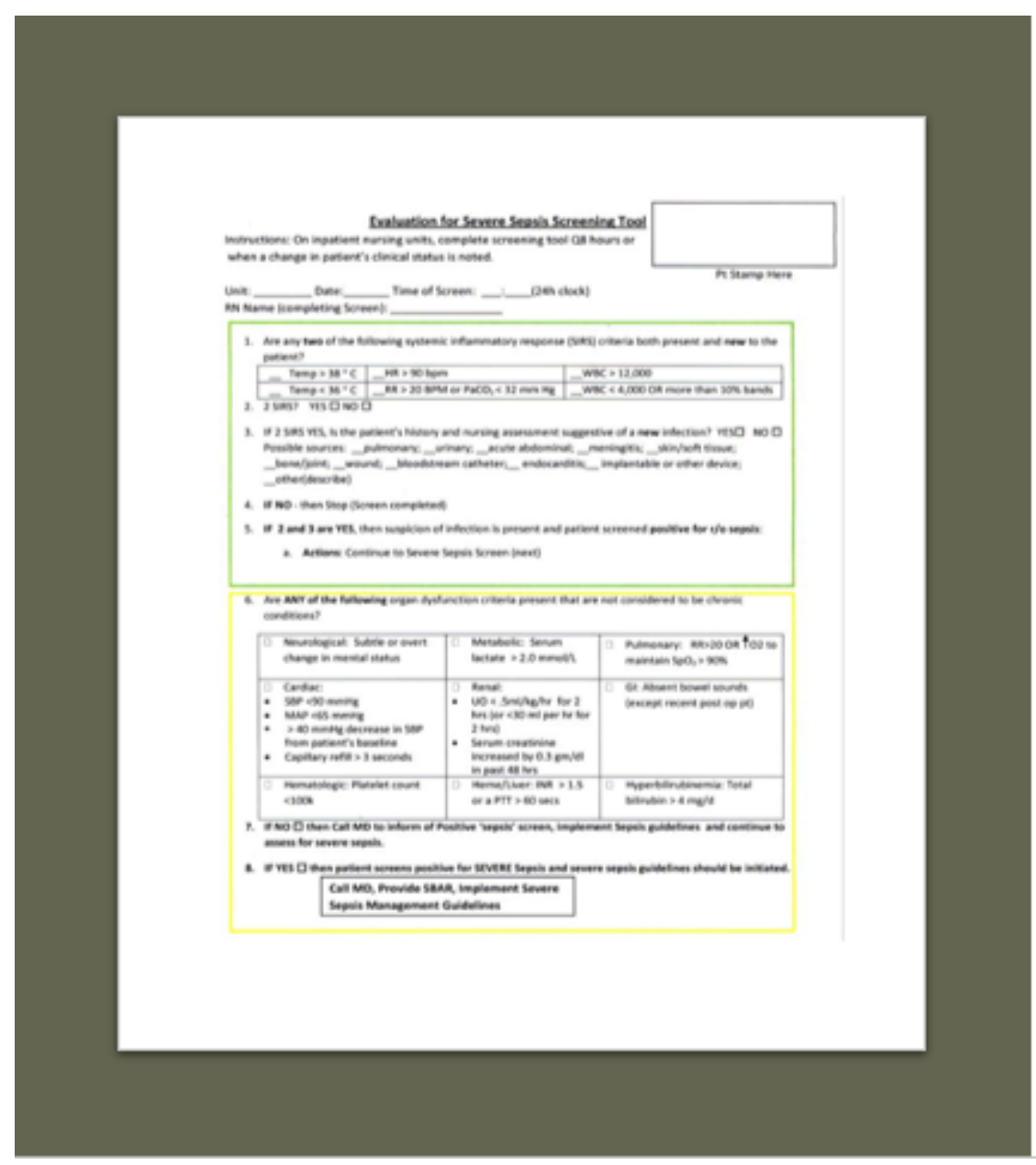

\section{Screening Tool}




\section{Protocol for treatment}
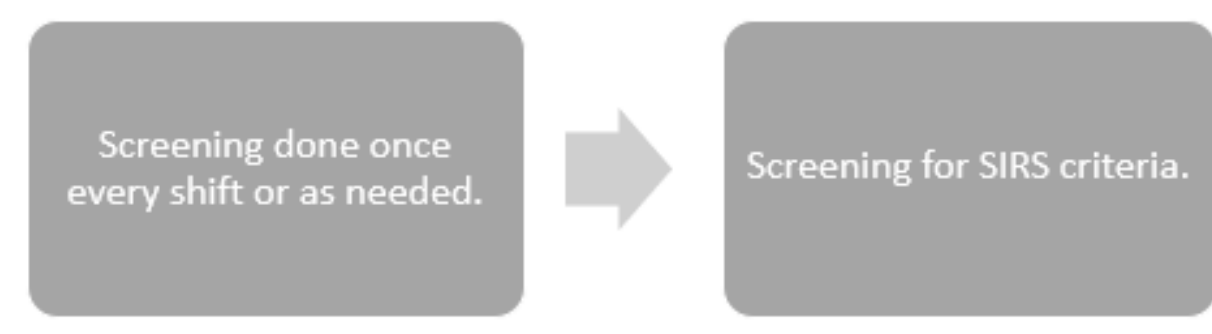

If positive identify possible

source of infection

If negative discontinue screening

Once source identified notify physician 
Protocol for treatment (Cont.)
- If source is identified, then continue assessment for severe sepsis

- If severe sepsis identified call physician or Rapid Response Team

- Document time of physician notification and time of treatment initiation 


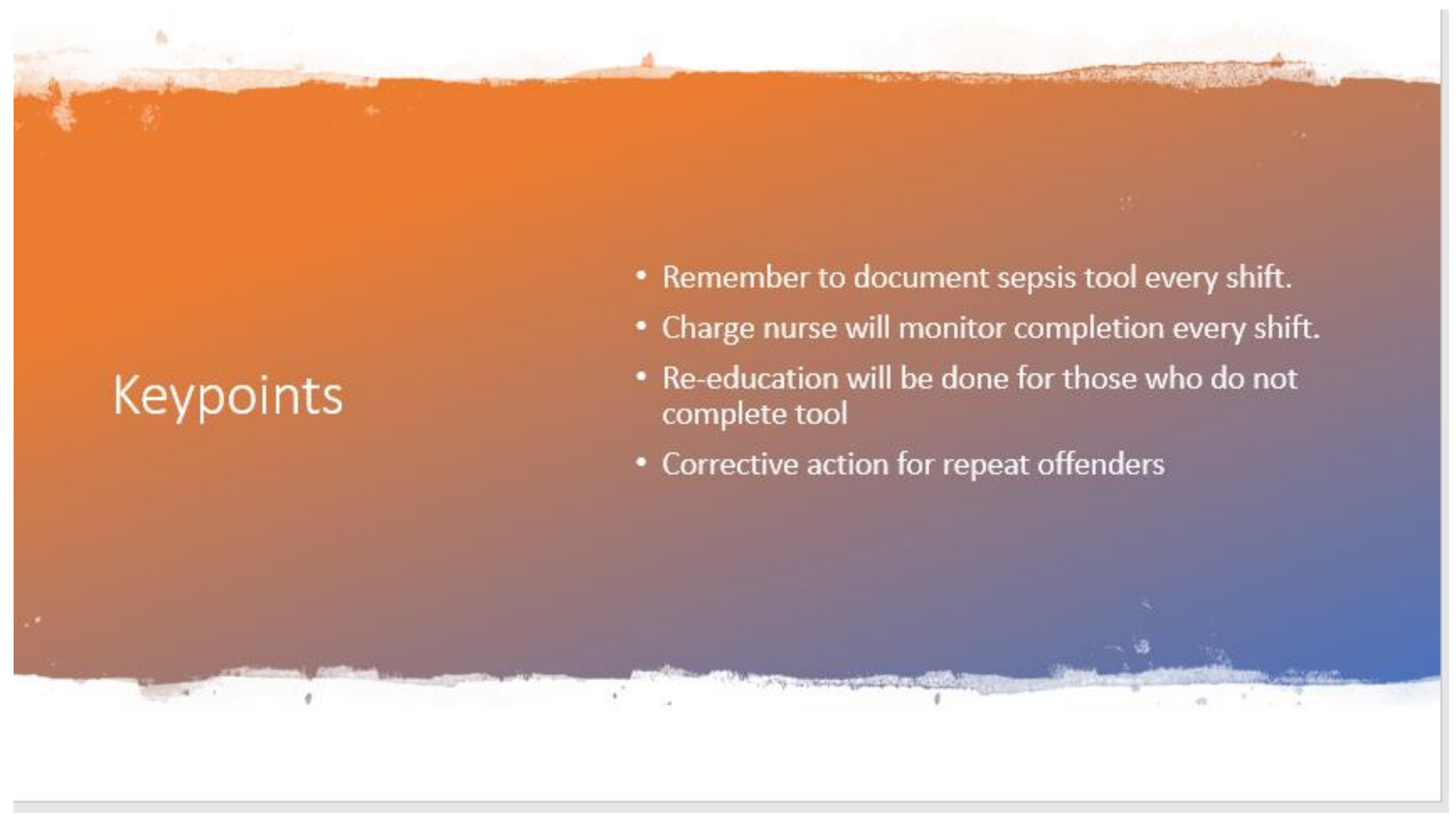




\section{Appendix G}

\section{Project Schedule}

\begin{tabular}{|c|c|c|c|c|c|c|c|c|c|c|c|c|c|c|c|c|c|c|c|c|c|c|c|c|}
\hline & NU & 801 & & & & & & & & R780 & & & & & & & & R780 & & & & & & \\
\hline : & $\begin{array}{l}\bar{y} \\
\bar{u} \\
3\end{array}$ & $\begin{array}{l}m \\
\frac{\pi}{\Delta} \\
z\end{array}$ & $\begin{array}{l}n \\
\text { ü } \\
3 \\
3\end{array}$ & $\begin{array}{l}\frac{\pi}{u} \\
\frac{u}{3}\end{array}$ & $\begin{array}{l}a \\
\frac{1}{0} \\
3\end{array}$ & $\begin{array}{l}= \\
\frac{u}{0} \\
3\end{array}$ & $\begin{array}{l}m \\
\frac{n}{J} \\
z\end{array}$ & $\begin{array}{l}n \\
\frac{n}{J} \\
3\end{array}$ & $\begin{array}{l}\bar{y} \\
\bar{d} \\
3\end{array}$ & $\begin{array}{l}m \\
\frac{u}{\Delta} \\
3\end{array}$ & $\begin{array}{l}n \\
\frac{u}{d} \\
3\end{array}$ & $\begin{array}{l}\frac{1}{u} \\
\frac{0}{3} \\
\end{array}$ & $\begin{array}{l}a \\
\dot{d} \\
j \\
3\end{array}$ & $\begin{array}{l}= \\
\ddot{d} \\
3\end{array}$ & $\begin{array}{l}\frac{m}{y} \\
\frac{y}{d} \\
3\end{array}$ & $\begin{array}{l}\frac{n}{u} \\
\frac{\pi}{d} \\
3\end{array}$ & $\begin{array}{l}\bar{y} \\
\overline{0} \\
3\end{array}$ & $\begin{array}{l}m \\
\ddot{u} \\
\tilde{u}\end{array}$ & $\begin{array}{l}n \\
\frac{\pi}{0} \\
z\end{array}$ & $\begin{array}{l}\frac{\pi}{u} \\
\frac{0}{3} \\
z\end{array}$ & $\begin{array}{l}a \\
\frac{1}{0} \\
3\end{array}$ & $\begin{array}{l}z \\
\bar{u} \\
3 \\
3\end{array}$ & $\begin{array}{l}m \\
\frac{m}{d} \\
z\end{array}$ & $\begin{array}{l}n \\
\frac{\pi}{0} \\
3\end{array}$ \\
\hline Meet with preceptor & $\mathrm{X}$ & $\mathrm{X}$ & $\mathrm{X}$ & $\mathrm{X}$ & $\mathrm{X}$ & $\mathrm{X}$ & $\mathrm{X}$ & $\mathrm{X}$ & $\mathrm{X}$ & $X$ & $\mathrm{X}$ & $\mathrm{X}$ & $\mathrm{X}$ & $\mathrm{X}$ & $\mathrm{X}$ & $\mathrm{X}$ & $\mathrm{X}$ & $\mathrm{X}$ & $x$ & $\mathrm{X}$ & $\mathrm{X}$ & $x$ & $x$ & $\mathrm{X}$ \\
\hline Prepare project proposal & $\mathrm{X}$ & & & & & & & & & & & & & & & & & & & & & & & \\
\hline Organizational assessment and Literature review & $\mathrm{X}$ & $\mathrm{X}$ & & & & & & & & & & & & & & & & & & & & & & \\
\hline Review requirements for IRB process & & & & & & & & & $\mathrm{X}$ & & & & & & & & & & & & & & & \\
\hline Submit for IRB approval from USA & & & & & & & & & $\mathrm{X}$ & & & & & & & & & & & & & & & \\
\hline Submit for IRB approval from site & & & & & & & & & & $X$ & & & & & & & & & & & & & & \\
\hline Receive IRB approval & & & & & & & & & & & $\mathrm{X}$ & & & & & & & & & & & & & \\
\hline Develop interdisciplinary team & & & & & & & & & & & & $\mathrm{X}$ & & & & & & & & & & & & \\
\hline Work with informaticist to integrate tool into EHR & & & & & & & & & & & & $\mathrm{X}$ & & & & & & & & & & & & \\
\hline Initiate training for staff & & & & & & & & & & & & $\mathrm{X}$ & & & & & & & & & & & & \\
\hline $\begin{array}{l}\text { Conduct pre implementation assessment and } \\
\text { collection of data pre-implementation }\end{array}$ & & & & & & & & & & & & $\mathrm{X}$ & $\mathrm{X}$ & & & & & & & & & & & \\
\hline Ongoing assessment of use of tool & & & & & & & & & & & & & & $\mathrm{X}$ & $\mathrm{X}$ & $\mathrm{X}$ & $\mathrm{X}$ & $\mathrm{X}$ & & & & & & \\
\hline Data collection & & & & & & & & & & & & $\mathrm{X}$ & $\mathrm{X}$ & $\mathrm{X}$ & $\mathrm{X}$ & $\mathrm{X}$ & $\mathrm{X}$ & $\mathrm{X}$ & & & $\mathrm{X}$ & & & \\
\hline Data analysis & & & & & & & & & & & & & & & & & & & $x$ & $\mathrm{X}$ & & & & \\
\hline Evaluation of project & & & & & & & & & & & & & & & & & & & & & $\mathrm{X}$ & & & \\
\hline Dissemination of findings to key stakeholders & & & & & & & & & & & & & & & & & & & & & & $x$ & & \\
\hline Sustainability plan to sepsis coordinator & & & & & & & & & & & & & & & & & & & & & & & X & \\
\hline Final project defense & & & & & & & & & & & & & & & & & & & & & & & & $\mathrm{X}$ \\
\hline
\end{tabular}




\section{Appendix H}

Table H1

Data Collection Form

\begin{tabular}{|c|c|c|c|c|c|c|c|}
\hline $\begin{array}{l}\text { Participant } \\
\text { ID }\end{array}$ & $\begin{array}{l}\text { Length } \\
\text { of stay }\end{array}$ & $\begin{array}{l}\text { Admission } \\
\text { diagnosis }\end{array}$ & $\begin{array}{l}\text { Discharge } \\
\text { diagnosis }\end{array}$ & $\begin{array}{l}\text { SIRS } \\
\text { criteria } \\
\text { met } \\
\text { Yes/No }\end{array}$ & $\begin{array}{l}\text { Time of } \\
\text { sepsis } \\
\text { recognition }\end{array}$ & $\begin{array}{l}\text { Time } \\
\text { physician } \\
\text { notified }\end{array}$ & $\begin{array}{l}\text { Transfer to } \\
\text { higher level } \\
\text { of care }\end{array}$ \\
\hline & & & & & & & \\
\hline & & & & & & & \\
\hline & & & & & & & \\
\hline & & & & & & & \\
\hline & & & & & & & \\
\hline & & & & & & & \\
\hline & & & & & & & \\
\hline & & & & & & & \\
\hline & & & & & & & \\
\hline
\end{tabular}




\section{Table H2}

Analysis of Evaluation Data

\begin{tabular}{|c|c|c|c|c|}
\hline Measures & Benchmark & Goal & $\begin{array}{l}\text { Current } \\
\text { Statistics }\end{array}$ & Statistical Test \\
\hline $\begin{array}{l}\text { Outcome measure } \\
\text { Rate of Severe } \\
\text { Sepsis/Septic shock }\end{array}$ & $\begin{array}{l}40 \% \text { (pre- } \\
\text { implementation rate } \\
\text { of severe sepsis) }\end{array}$ & $\leq 39 \%$ & $3.33 \%$ & $\begin{array}{l}\mathrm{x}^{2}, \text { frequency, } \\
\text { percentage }\end{array}$ \\
\hline $\begin{array}{l}\text { Outcome measure } \\
\text { Rate of patients' timely } \\
\text { notification of physician }\end{array}$ & $41 \%$ (Current rate) & $\leq 42 \%$ & $59 \%$ & $\begin{array}{l}\mathrm{x}^{2} \\
\text { frequency, } \\
\text { percentage }\end{array}$ \\
\hline $\begin{array}{l}\text { Process Measure } \\
\text { Percent of staff } \\
\text { completing tool Q shift }\end{array}$ & $100 \%$ & $\geq 95 \%$ & $100 \%$ & $\begin{array}{l}\text { frequency, } \\
\text { percentage }\end{array}$ \\
\hline $\begin{array}{l}\text { Balance Measure } \\
\text { Length of Stay }\end{array}$ & $\begin{array}{l}8.1 \text { days (current } \\
\text { LOS) }\end{array}$ & $\begin{array}{l}\leq 4.8 \\
\text { days }\end{array}$ & $\leq 4.4$ days & frequency \\
\hline $\begin{array}{l}\text { Balance Measure } \\
\text { Number of transfers to } \\
\text { higher level of care }\end{array}$ & 10 & $\leq 9$ & 1 & frequency \\
\hline $\begin{array}{l}\text { Financial Measure } \\
\text { Cost of staff training }\end{array}$ & $\begin{array}{l}\$ 91,274 \text { (Cost of } \\
\text { training } 630 \mathrm{RNs} \text { at } \\
\text { the cost of } \\
\$ 72.44 / \mathrm{hr} \text {. for } 2 \\
\text { hrs.) }\end{array}$ & & & \\
\hline $\begin{array}{l}\text { Sustainability } \\
\text { measures } \\
\text { Percent of education of } \\
\text { new hires }\end{array}$ & $100 \%$ & $\geq 95 \%$ & & $\begin{array}{l}\text { frequency, } \\
\text { percentage }\end{array}$ \\
\hline
\end{tabular}




\section{Appendix $\mathbf{H}$}

\section{Figure H1}

\section{Sepsis Incidences}

\section{Sepsis/Severe Sepsis}

Study

Preimplementation

- Postimplementation

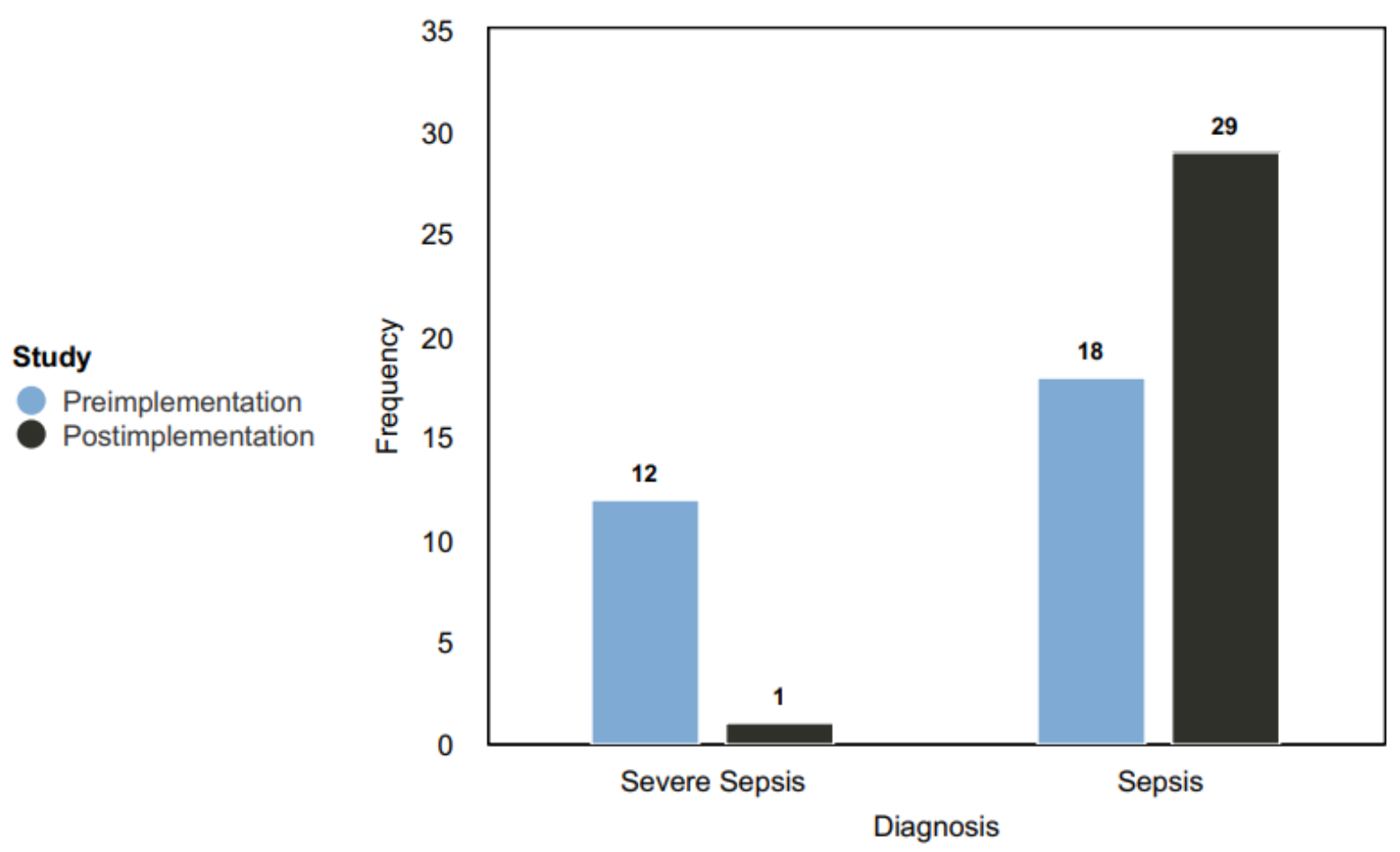


Figure H2

Physician Notification time

Physician Notification

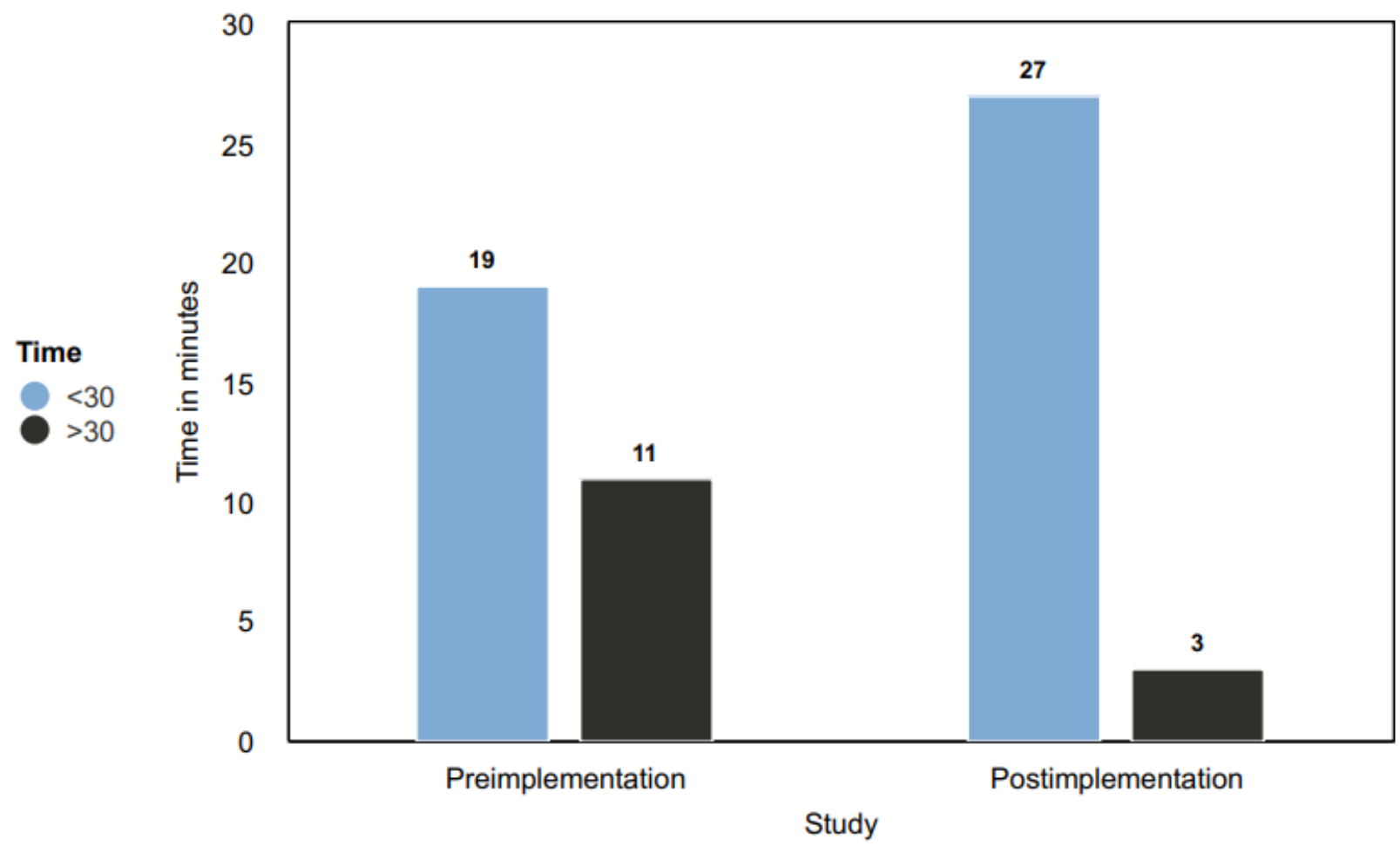




\section{Figure H3}

\section{Length of Stay}

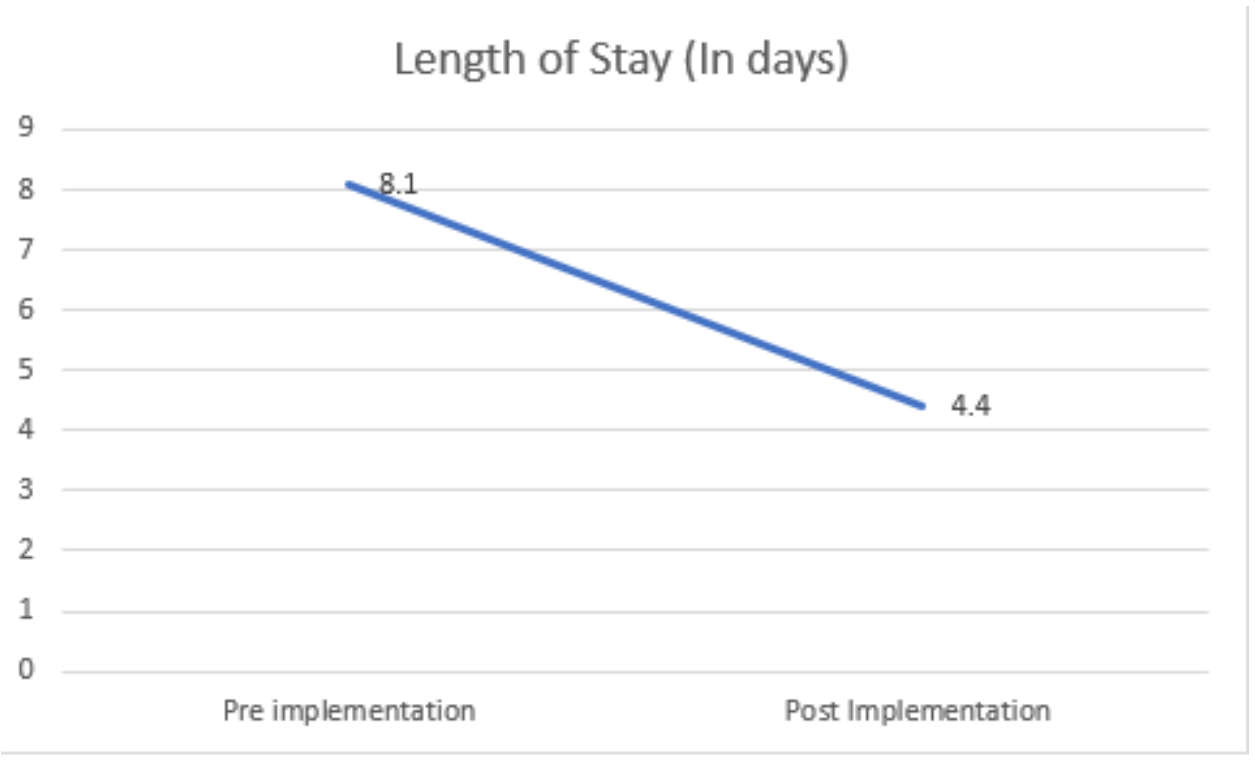

